\title{
Elimination of Microglia Improves Functional Outcomes Following Extensive Neuronal Loss in the Hippocampus
}

\author{
Rachel A. Rice, ${ }^{1}$ Elizabeth E. Spangenberg, ${ }^{1}$ Hana Yamate-Morgan, ${ }^{1}$ Rafael J. Lee, ${ }^{1}$ Rajan P. S. Arora, ${ }^{1}$ \\ ๑Michael X. Hernandez, ${ }^{1}$ Andrea J. Tenner, ${ }^{1}$ Brian L. West,${ }^{2}$ and Kim N. Green ${ }^{1}$ \\ ${ }^{1}$ Department of Neurobiology and Behavior, Institute for Memory Impairments and Neurological Disorders, University of California, Irvine, California \\ 92697, and 2Plexxikon, Inc., Berkeley, California 94710
}

\begin{abstract}
With severe injury or disease, microglia become chronically activated and damage the local brain environment, likely contributing to cognitive decline. We previously discovered that microglia are dependent on colony-stimulating factor 1 receptor (CSF1R) signaling for survival in the healthy adult brain, and we have exploited this dependence to determine whether such activated microglia contribute deleteriously to functional recovery following a neuronal lesion. Here, we induced a hippocampal lesion in mice for $25 \mathrm{~d}$ via neuronal expression of diphtheria toxin A-chain, producing both a neuroinflammatory reaction and behavioral alterations. Following the $25 \mathrm{~d}$ lesion, we administered PLX3397, a CSF1R inhibitor, for $30 \mathrm{~d}$ to eliminate microglia. This post-lesion treatment paradigm improved functional recovery on elevated plus maze and Morris water maze, concomitant with reductions in elevated proinflammatory molecules, as well as normalization of lesion-induced alterations in synaptophysin and PSD-95. Further exploration of the effects of microglia on synapses in a second cohort of mice revealed that dendritic spine densities are increased with long-term microglial elimination, providing evidence that microglia shape the synaptic landscape in the adult mouse brain. Furthermore, in these same animals, we determined that microglia play a protective role during lesioning, whereby neuronal loss was potentiated in the absence of these cells. Collectively, we demonstrate that microglia exert beneficial effects during a diphtheria toxin-induced neuronal lesion, but impede recovery following insult.
\end{abstract}

Key words: behavior; glia; inflammation; lesion; spines; synapse

Significance Statement

It remains unknown to what degree, and by what mechanisms, chronically activated microglia contribute to cognitive deficits associated with brain insults. We induced a genetic neuronal lesion in mice for $25 \mathrm{~d}$ and found activated microglia to increase inflammation, alter synaptic surrogates, and impede behavioral recovery. These lesion-associated deficits were ameliorated with subsequent microglial elimination, underscoring the importance of developing therapeutics aimed at eliminating/modulating chronic microglial activation. Additionally, we found long-term microglial depletion globally increases dendritic spines by $\sim 35 \%$ in the adult brain, indicating that microglia continue to sculpt the synaptic landscape in the postdevelopmental brain under homeostatic conditions. Microglial manipulation can therefore be used to investigate the utility of increasing dendritic spine numbers in postnatal conditions displaying synaptic aberrations.

\section{Introduction}

Microglia are the primary immune cell of the CNS and represent the first line of defense against pathogens, comprising $\sim 10 \%$ of

Received Jan. 26, 2015; revised May 13, 2015; accepted June 1, 2015.

Author contributions: R.A.R., A.J.T., B.L.W., and K.N.G. designed research; R.A.R., E.E.S., H.Y.-M., R.J.L., R.P.S.A., and M.X.H. performed research; R.A.R., E.E.S., H.Y.-M., R.J.L., R.P.S.A., and M.X.H. analyzed data; R.A.R. and K.N.G. wrote the paper.

This work was supported by the National Institutes of Health under awards 1R01NS083801 (NINDS) and P50 AG016573 (NIA) to K.N.G., F31NS086409 (NINDS) to R.A.R., PPG AG 00538 (NIA) to A.J.T., T32 AG000096 (NIA) to M.X.H., the Whitehall Foundation to K.N.G., American Federation of Aging Research to K.N.G., and the Alzheimer's Association to K.N.G. The content is solely the responsibility of the authors and does not necessarily represent the official views of the National Institutes of Health. cells in the brain (Pessac et al., 2001). They exist in a quiescent state, whereby they constantly survey the local environment for any infectious agents or cellular debris (Nimmerjahn et al., 2005). The presence of such initiates a cascade of events culminating in the physical and chemical remodeling of microglia into a spectrum of "activated" states designed to attack pathogens and clear debris, through the production of proinflammatory cytokines

B.L.W. is an employee of Plexxikon, Inc. The remaining authors declare no competing financial interests.

Correspondence should be addressed to Dr Kim N. Green, 3208 Biological Sciences III, University of California, Irvine, Irvine, CA 92697-4545. E-mail: kngreen@uci.edu.

DOI:10.1523/JNEUROSCI.0336-15.2015

Copyright $\odot 2015$ the authors $\quad 0270-6474 / 15 / 359977-13 \$ 15.00 / 0$ 
such as TNF- $\alpha$, IL-1 $\beta$, and IL-6 (Renno et al., 1995; Liu et al., 1998). Finally, microglia take on an anti-inflammatory role, secreting molecules such as IL-4 and IL-10 as part of the resolution and repair process, before returning to a surveillant state (Colton and Wilcock, 2010).

We have previously shown that microglia and related myeloid cells in the healthy adult brain are fully and uniquely dependent upon signaling through the colony-stimulating factor 1 receptor (CSF1R), and that administration of the CSF1R/c-kit inhibitor PLX3397 leads to the rapid elimination of $>95 \%$ of all microglia within 7-21 d (Elmore et al., 2014). This approach provides us with a useful tool to directly study microglial functions, as microglia are the only cell type to express CSF1R in the postnatal brain parenchyma under normal conditions (Sierra et al., 2007; Erblich et al., 2011). Importantly, previous research by our group has shown that the elimination of microglia does not induce an inflammatory response in the brain (Elmore et al., 2014). Microglia are negatively implicated in most neurodegenerative disorders and brain injuries, where they mount neuroinflammatory responses that are never, or poorly, resolved. As an example, it has been shown that patients who suffered a traumatic brain injury (TBI) have substantially activated microglia 17 years later (Ramlackhansingh et al., 2011). Moreover, the targeting of certain proinflammatory molecules alone, such as IL- $1 \beta$ or TNF- $\alpha$, can improve cognitive deficits associated with Alzheimer's disease (Tobinick and Gross, 2008; Kitazawa et al., 2011). Thus, it is essential to determine whether chronically activated microglia are also dependent upon CSF1R signaling, and so can be eliminated with CSF1R inhibitors, allowing for the direct roles of microglia in disease and injury states to be explored.

\section{Materials and Methods}

Compounds. PLX3397 was provided by Plexxikon and formulated in standard chow by Research Diets at $290 \mathrm{mg} / \mathrm{kg}$. Doxycycline was provided in standard chow by Research Diets at $2000 \mathrm{mg} / \mathrm{kg}$, or by researchers (Sigma-Aldrich) in deionized drinking water at $2 \mathrm{mg} / \mathrm{ml}$ with $5 \%$ sucrose.

Animal treatments. All rodent experiments were performed in accordance with animal protocols approved by the Institutional Animal Care and Use Committee at the University of California, Irvine (UCI). The bitransgenic CaM/Tet-DT $\mathrm{A}_{\mathrm{A}}$ mouse model of inducible neuronal loss was used for functional studies, and has been previously described (Yamasaki et al., 2007). Triple transgenic GFP-CaM/Tet mice were used for experiments involving dendritic spine analyses, and have been previously described (Castello et al., 2014). Five to 8-month-old male and female mice were maintained since birth on doxycycline chow. Upon induction of the $25 \mathrm{~d}$ lesion period, doxycycline chow was replaced with standard chow. To cease expression of diphtheria toxinA-chain $\left(\mathrm{DT}_{\mathrm{A}}\right)$, doxycycline was provided in drinking water, and control or PLX3397 chow was provided for the final $30 \mathrm{~d}$. Behavioral tasks were performed during the final week of the study. At the conclusion of experiments, mice were killed via lethal intraperitoneal injection of Euthasol (Virbac $\mathrm{AH}$ ) and perfused transcardially with $1 \times$ PBS. Brains were extracted and dissected down the midline, with one-half flash-frozen on dry ice for subsequent RNA and protein analyses, and the other one-half drop-fixed in $4 \%$ paraformaldehyde (PFA) in $1 \times$ PBS. Fixed brains were cryopreserved in a $30 \%$ sucrose solution, frozen, and sectioned at $40 \mu \mathrm{m}$ on a Leica SM2000 R sliding microtome for subsequent immunohistochemical analyses. Twomonth-old wild-type mice were treated with PLX3397 for 1, 3, or $7 \mathrm{~d}$ to assess IL- $1 \beta$ levels in the brain. Mice were killed via $\mathrm{CO}_{2}$ inhalation and transcardially perfused with ice-cold $1 \times$ PBS. Brains were dissected down the midline and one-half was homogenized in Tissue Protein Extraction Reagent (TPER; Life Technologies), with protease (Roche) and phosphatase inhibitors (Sigma-Aldrich) for subsequent ELISA analysis.

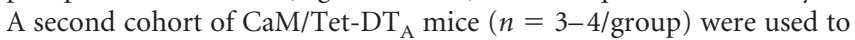
assess the integrity of the blood-brain barrier, via Evans blue (EB) and flow cytometry assays. Mice were maintained on doxycycline since birth and aged to 11 months, at which point doxycycline was withdrawn from the diet for $25 \mathrm{~d}$ to induce a neuronal lesion. Mice were killed via $\mathrm{CO}_{2}$ inhalation and transcardially perfused with ice-cold $1 \times$ PBS.

Confocal microscopy. Fluorescent immunolabeling followed a standard indirect technique (primary antibody followed by fluorescent secondary antibody) as previously described (Neely et al., 2011). Primary antibodies used include NeuN (1:1000; Abcam), IBA1 (1:1000; Wako), GFAP (1: 10,000; Abcam), CD169 (1:50; AbD Serotec), synaptophysin (1:500; Sigma-Aldrich), and PSD95 (1:1000; Cell Signaling Technology). The size of microglia cell bodies, PSD95 puncta, and synaptophysin puncta was determined using the surface module in Imaris 7.5 software. Numbers of microglia, astrocytes, PSD95 puncta, and synaptophysin puncta were determined using the spots module in Imaris 7.5 software.

ELISA analysis. Half-brain TPER homogenates were analyzed for IL- $1 \beta$ levels using a commercially available ELISA kit (eBioscience).

$E B$ analysis of blood-brain barrier integrity. After $25 \mathrm{~d}$ of doxycycline withdrawal, three control and three lesion mice were given an intraperitoneal injection $6 \mathrm{~h}$ before kill with a $2 \%$ solution of EB (Sigma-Aldrich) in $1 \times \mathrm{PBS}$ at $4 \mathrm{ml} / \mathrm{kg}$ of body weight. An additional lesion mouse was not injected with EB. Upon kill, half-brains, spleens, and livers were harvested and homogenized in $1 \mathrm{ml} 1 \times \mathrm{PBS}$ and centrifuged to produce a supernatant. To the supernatant, one equal volume of 50\% trichloroacetic acid (Sigma-Aldrich) was added and allowed to incubate overnight. The absorbance of the solution at $595 \mathrm{~nm}$ was measured by spectrophotometry. The absorbance reading from the organs of the lesion mouse that was not injected with EB served as a blank and was subtracted from the other sample readings.

Microglial isolation. Briefly, half-brains were collected into ice-cold Dulbecco's Modified Eagle Medium without phenol red (Life Technologies). Tissue was passed through a $70 \mu \mathrm{m}$ filter and centrifuged. The supernatant was discarded and the pellet was resuspended in 70\% Percoll solution in $1 \times$ PBS (GE Healthcare). To this, 50, 35, and $0 \%$ Percoll solutions were overlaid. Following centrifugation, the $50-70 \%$ interface was collected to take the microglia-containing fraction. Cells were resuspended in DMEM without phenol red and centrifuged again. The supernatant was discarded and the pellet washed with $1 \times$ PBS $+2 \%$ bovine serum albumin (BSA).

Flow cytometry. Isolated microglia were incubated for $30 \mathrm{~min}$ with PE-CD45 (1:100; Tonbo Biosciences) and PE-Cy7-CD11b (1:100; eBioscience) antibodies separately and together, as well as with individual isotype controls for PE (1:100; Tonbo Biosciences) and PE-Cy7 (1:100; eBioscience). Cells were washed three times and resuspended in $1 \times$ PBS with $2 \%$ BSA (Thermo Fisher Scientific) before proceeding to analysis. Cell populations were gated by forward scatter and side scatter, for size and granularity, respectively, to determine the live cell population. Isotype controls directed initial gating of $\mathrm{CD} 11 \mathrm{~b}^{+}, \mathrm{CD} 45^{+}$populations. Total live cells were then gated for PE-Cy7 fluorescence to define the $\mathrm{CD} 11 \mathrm{~b}^{+}$subpopulation. This subpopulation was then further gated for $\mathrm{PE}$ fluorescence to define $\mathrm{CD} 45^{+}$cells, which were then divided into low/moderate and high $\mathrm{CD} 45^{+}$populations. PE and PE-Cy7 fluorophores were chosen so as not to interfere with the emission spectrum of Evans blue dye.

Stereology. Cresyl violet staining was performed on fixed tissue and neurons in the CA1 region were counted via stereological analysis, as previously described (Myczek et al., 2014). IBA1 (1:1000, Wako) labeling was performed on fixed tissue using Vectastain Elite ABC and DAB Peroxidase Substrate kits (Vector Laboratories), and microglia in the hippocampus were counted via stereological analysis, as previously described (Myczek et al., 2014).

Behavioral testing. Mouse cognition and behavior were evaluated on open-field test (Elmore et al., 2014), elevated plus maze (Elmore et al., 2014), and Morris water maze (Baglietto-Vargas et al., 2013), in that order, as previously described.

$m R N A$ extraction and $q P C R$. RNA was extracted and purified from microdissected hippocampi of frozen half-brains, and then real-time PCR performed with Taqman Array Mouse Immune Panel cards (Thermo Fisher Scientific), as per the manufacturers instructions. Values were calculated as $\delta$ - $\delta C \mathrm{t}$, as previously described by Elmore et al. (2014). 
Dendritic spine analyses. For the GFP-CaM/Tet mice, five nonprimary apical dendrites in both the CA1 of the hippocampus and layer 5 of cortical area V1 were imaged on a Leica DM2500 confocal microscope with $63 \times$ oil-objective and $5 \times$ digital zoom. Z-stacks of equal depth were obtained for each dendrite, deconvolved using Huygens deconvolution software, and max projections created. From the max projections, two researchers independently counted and classified spines using the Cell Counter plug-in in ImageJ software. Spine classification was based on previous literature in the field using head-to-neck ratio (Peters and Kaiserman-Abramof, 1970). Finally, the total number of each type of spine was calculated per $10 \mu \mathrm{m}$ of dendrite length.

Statistics. Two-way ANOVAs were used to analyze differences between all four groups of mice (Diet: control vs PLX3397; Genotype: nonlesion vs lesion) using GraphPad Prism or Statistical Analysis Systems (SAS) software (SAS Institute). Repeated measures two-way ANOVA was used to analyze Morris water maze training over 5 d (Diet: control vs PLX3397; Genotype: nonlesion vs lesion; Repeated: trial number) using SAS (SAS Institute). One-way ANOVA was used to analyze IL- $1 \beta$ levels using GraphPad Prism. Two-tailed unpaired Student's $t$ test was used to determine differences between control and lesion mice for blood-brain barrier analyses. For two-way ANOVA, post hoc paired contrasts were used to examine biologically relevant interactions from the two-way ANOVA regardless of statistical significance of the interaction. Results are presented as raw average \pm SEM. Significance is defined as $p<0.05$, unless otherwise indicated. The following symbols are used to denote significant differences between groups, as obtained by post hoc analyses: †control versus PLX3397; * control versus lesion; $\phi$ PLX3397 versus lesion + PLX3397; \#lesion versus lesion + PLX3397.

\section{Results}

\section{Activated microglia are dependent upon signaling through the CSF1R}

We first set out to determine whether chronically activated microglia are dependent upon CSF1R signaling, as these cells are in the healthy brain (Elmore et al., 2014). To make this disease- and injury-relevant, we used a tetracycline-off inducible doubletransgenic system, in which we can control the expression of $\mathrm{DT}_{\mathrm{A}}$ in forebrain neurons (CaM/Tet-DT $\mathrm{T}_{\mathrm{A}}$ mice; Yamasaki et al., 2007), as shown in Figure $1 A$, and chose to treat animals with PLX3397, a CSF1R/c-kit antagonist, after the lesioning period. Withdrawal of doxycycline from the diet of adult mice induces expression of $\mathrm{DT}_{\mathrm{A}}$, a potent cytotoxin for eukaryotic cells (Kochi and Collier, 1993), resulting in neuronal death, initially within the CA1 region (Yamasaki et al., 2007). Readministration of doxycycline $25 \mathrm{~d}$ later prevents any further neuronal loss, and results in a robust loss of CA1 neurons (as previously quantified by stereological methods) and marked behavioral deficits (Yamasaki et al., 2007).

Double-transgenic mice $\left(\mathrm{CaM} /\right.$ Tet- $\left.\mathrm{DT}_{\mathrm{A}}\right)$ were established by crossing TRE-DT A $_{\mathrm{A}}$ mice (Lee et al., 1998) with CaMKII $\alpha$-tTA mice (Mayford et al., 1996). In this paradigm, single-transgenic TRE-DT $\mathrm{A}_{\mathrm{A}}$ mice were generated to serve as nonlesioning controls, as they lack the CaMKII $\alpha$-tTA transgene and therefore cannot produce $\mathrm{DT}_{\mathrm{A}}$. Adult CaM/Tet-DT $\mathrm{D}_{\mathrm{A}}$ mice were divided into four experimental groups: (1) nonlesioned mice that received control chow ("control"; $n=8$ ), (2) nonlesioned mice that received PLX3397 chow ("PLX3397”; $n=8$ ), (3) lesioned mice that received control chow ("lesion"; $n=10$ ), and (4) lesioned mice that received PLX3397 chow ("lesion + PLX3397"; $n=10$; Fig. $1 A, B)$. Mice that underwent lesioning had significant neuronal loss in the CA1 and stratum radiatum, as measured by layer thickness after staining for NeuN (Fig. 1E).

Immunostaining for microglia with the marker IBA1 revealed robust increases in microglial densities with lesion alone; numbers in the hippocampal region were $207 \%$ that of control ani- mals (Fig. 1C,F). Both nonlesioned and lesioned mice treated with the CSF1R inhibitor PLX3397 for $30 \mathrm{~d}$ had $70-80 \%$ of $\mathrm{IBA}^{+}{ }^{+}$cells eliminated compared with control mice (Fig. 1C,F). Additionally, the body size of IBA $1^{+}$cells was increased by $\sim 80 \%$ in both PLX3397 treated groups of mice, consistent with our previous observations (Elmore et al., 2014), whereas astrocyte number was significantly increased only in the lesion + PLX3397 group (Fig. $1 G-J$ ).

It is important to note that the elimination of microglia, via CSF1R inhibition, does not cause elevation of inflammatory cytokines. We previously characterized $\sim 80$ inflammation related genes at the mRNA level after $7 \mathrm{~d}$ of PLX3397 treatment and found all to be decreased or unchanged with the treatment (Elmore et al., 2014). We suspect this is because all surviving microglia have their CSF1R inhibited, and this may prevent a reaction to the death of neighbor cells. To confirm a lack of increased inflammatory signaling this at the protein level, we assessed Il-1 $\beta$ levels in brain homogenates of wild-type mice treated with PLX3397 for 1, 3, and $7 \mathrm{~d}$, and find a significant reduction with $7 \mathrm{~d}$ of treatment, when $\sim 70 \%$ of microglia have been eliminated (Fig. 2A). Thus, elimination of microglia via CSF1R inhibition does not increase, but actually decreases levels of IL- $1 \beta$, a canonical proinflammatory marker.

\section{Neuronal lesioning does not induce migration of peripheral myeloid cells to the brain}

Infiltration of peripheral myeloid cells into the CNS has been described with conditions that compromise the blood-brain barrier. Given the increase in IBA1 ${ }^{+}$cells following lesioning in our model, we believed it plausible that these cells were of peripheral origin. We first sought to determine whether a $25 \mathrm{~d}$ neuronal lesion grossly compromises the blood-brain barrier. To this end,

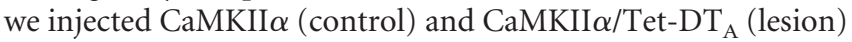
mice with EB dye following the lesioning period in $(n=3-4$ / group). Whereas peripheral organs from control and lesion mice displayed EB staining, no dye was found in the brains of animals from either group, nor was absorbance of EB detected by spectrophotometry (Fig. $2 B, C$ ). Despite finding that the blood-brain barrier was not compromised, other events can allow for the infiltration of peripheral myeloid cells. Indeed, peripheral injury, as well as a model of repeated social defeat, are known to increase both circulating monocyte numbers and the recruitment of peripheral myeloid cells to the brain (D'Mello et al., 2009; Wohleb et al., 2013). We therefore performed flow cytometry analyses on these same mice to determine whether lesioning increased the number of $\mathrm{CD} 11 \mathrm{~b}^{+} / \mathrm{CD} 45^{\text {hi }}$ cells in the brain, which are considered to represent infiltrating cells (Greter et al., 2005; Wirenfeldt et al., 2005). Although the number of CD $45^{\text {hi }}$ cells was not changed in lesion mice compared with control mice, we did observe the average CD45 fluorescence intensity to be significantly higher in the CD $45^{\text {lo/mod }}$ cell population in lesion mice (Fig. $2 D-F)$. Finally, we also probed brain tissue from the larger CaM/ Tet-DT ${ }_{\mathrm{A}}$ cohort for IBA1 and CD169. CD169 is known to be a specific marker of bone marrow-derived monocytes and can be used to differentiate between microglia and infiltrating myeloid cells, such that the colocalization of IBA1 and CD169 would indicate that the IBA $1{ }^{+}$cells are peripherally derived (Butovsky et al., 2012; Gao et al., 2015). In all groups surveyed, we found no $\mathrm{IBA}^{+}$cells in the brain to also be $\mathrm{CD} 169^{+}$, though we confirmed the CD169 antibody positively labeled cells in peripheral thymus tissue (Fig. 2G). This finding indicates that the IBA1 ${ }^{+}$ cells present in brains 1 month after the end of lesion are microglia, and not monocytes/macrophages. 


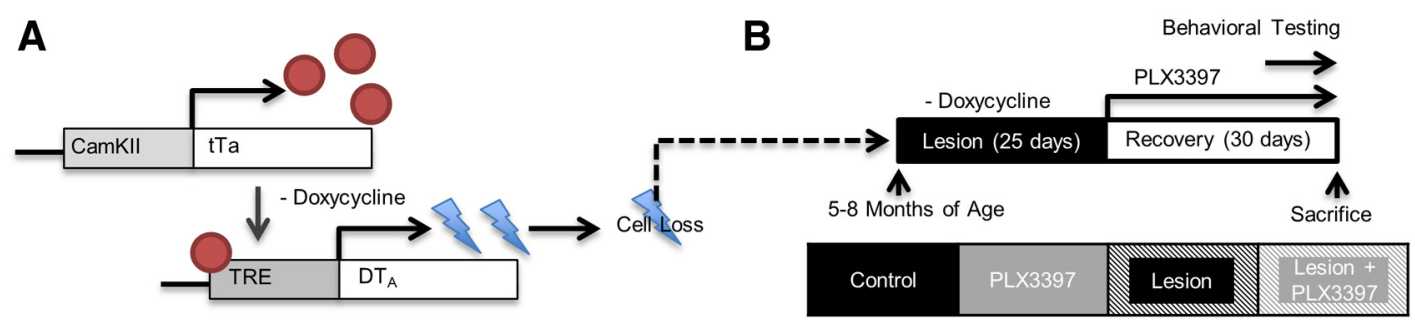

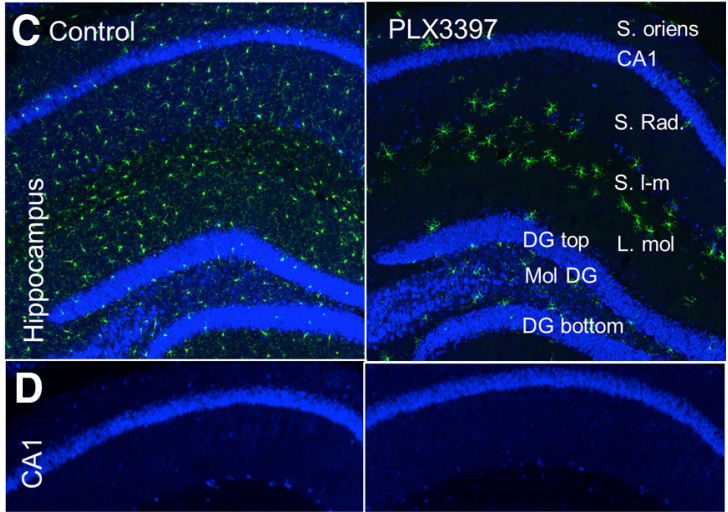

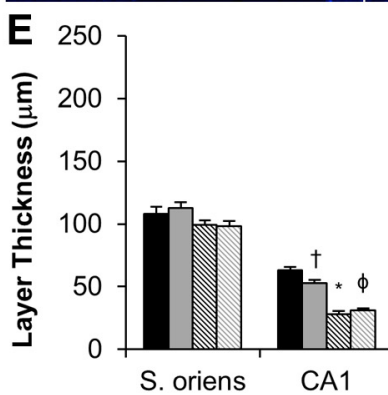

Cell Layer Thickness

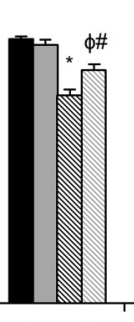

S. rad.

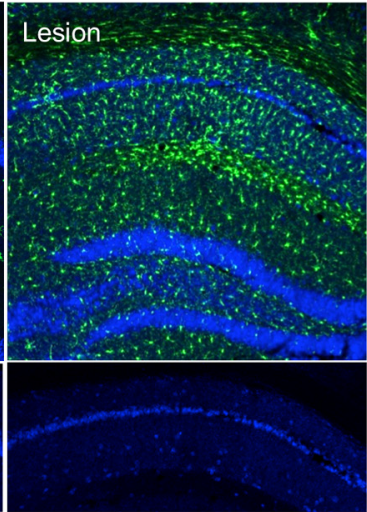

- Control

口PLX3397

$\mathbb{Q}$ Lesion

口Lesion + PLX3397

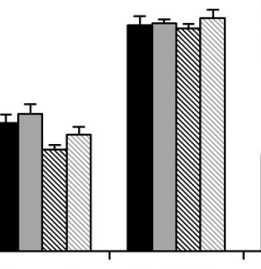

L. mol. MolDG

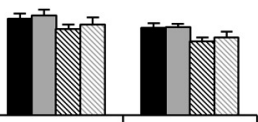

GC top GC bottom blade blade

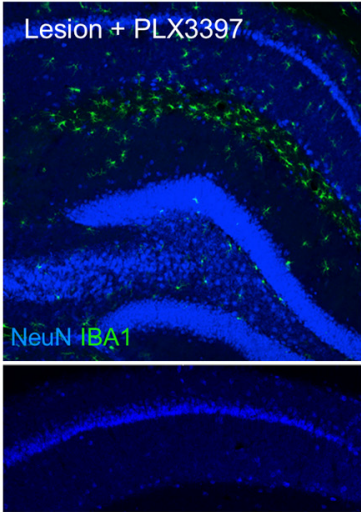

$\mathbf{F}$

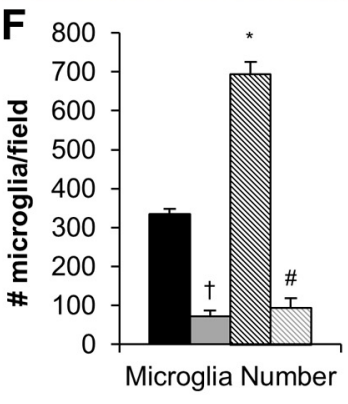

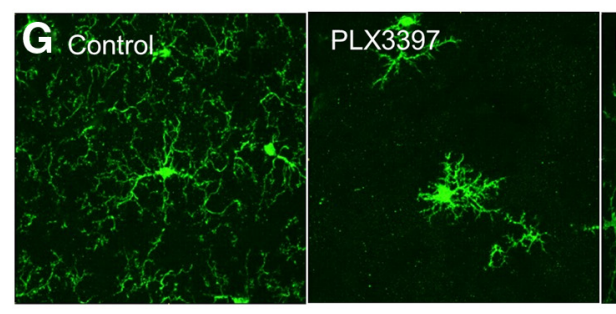
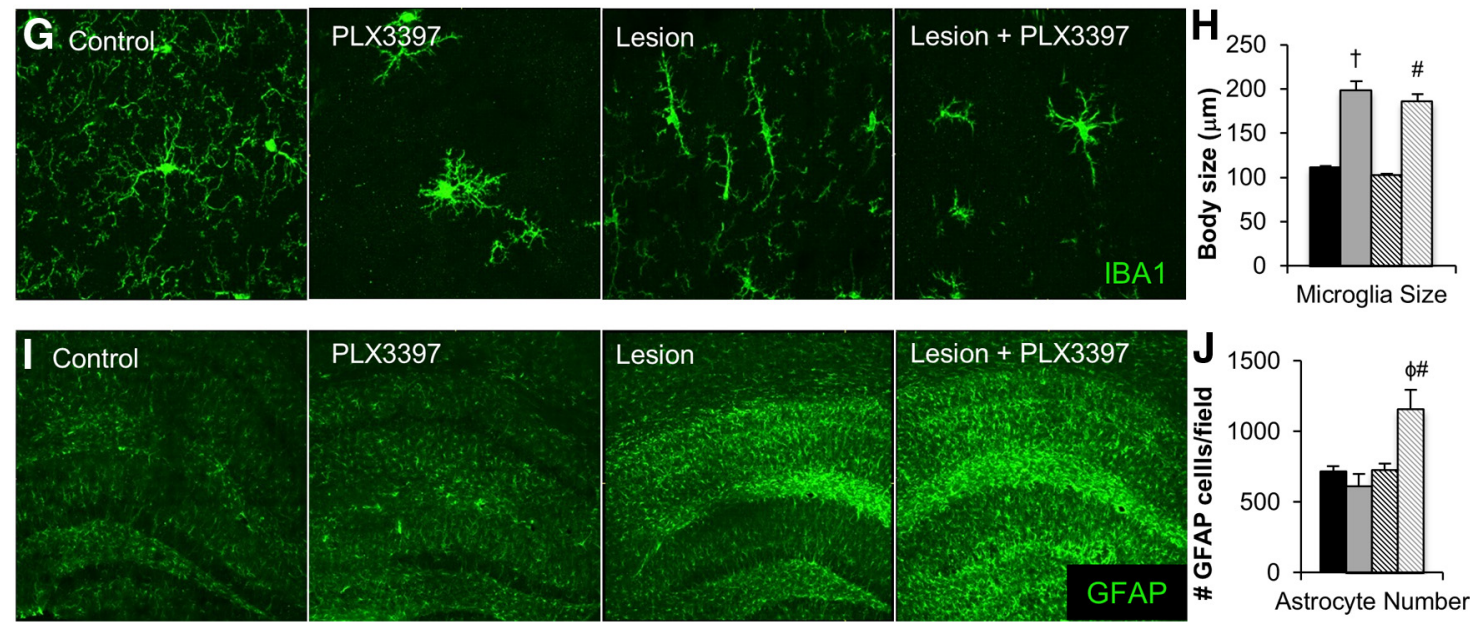

Figure 1. Lesion-induced activation does not affect dependence on CSF1R signaling for survival in microglia: 5 to 8-month-old CaM/Tet mice (C57BL/6) underwent a $25 \mathrm{~d}$ neuronal lesion and subsequent microglial elimination via treatment with $290 \mathrm{mg} / \mathrm{kg}$ PLX3397. A, B, Schematics of CaM/Tet mouse model of inducible neuronal loss and experimental design. C, D, Thickness of the CA1 layer is significantly decreased with lesion (via two-way ANOVA, main effect of lesion $p<0.0001$, interaction $p=0.0151$ ). $\boldsymbol{F}$, Number of microglia increases $>200 \%$ with lesion, but subsequent PLX3397 treatment eliminates $85 \%$ of all cells. $\mathbf{G}, \boldsymbol{H}$, Representative $63 \times$ IBA1 immunofluorescent staining from the hippocampal region. $\boldsymbol{I}, \boldsymbol{J}, 10 \times$ GFAP immunofluorescent staining of CA1 and dentate gyrus reveals increases in GFAP ${ }^{+}$cells in lesion + PLX3397. Symbols denote significant differences between groups $(p<0.05)$ : †control versus PLX3397; ${ }^{*}$ control versus lesion; $\phi P L X 3397$ versus lesion + PLX3397; \#lesion versus lesion + PLX3397. Error bars indicate SEM; $n=7-10 /$ group. S oriens, Stratum oriens; CA, cornus ammonis; S rad, stratum radiatum; S I-m, stratum lacunosum moleculare; L mol, molecular layer; DG, dentate gyrus.

Immune profiling of the lesioned and microglia-depleted brain

mRNA was extracted from frozen microdissected hippocampi from four mice from each group, converted to cDNA, and then analyzed against a panel of 86 immune-related genes ( $n=4$ /group; Fig. $3 A-$ F). Of the 86 immune-related genes, 60 reached detection threshold levels and are reported here. Lesioned mice had significant increases in mRNA expression levels for cytokine-related molecules $I l 15, I l 1 \alpha$, 
A

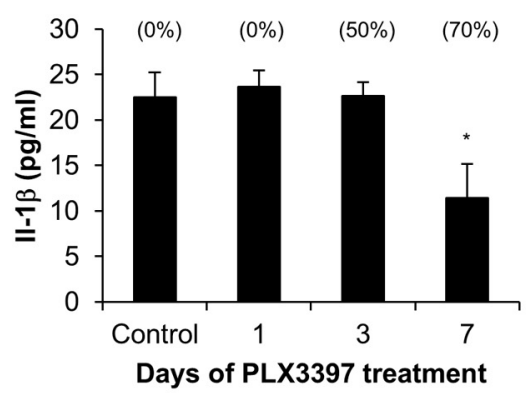

B

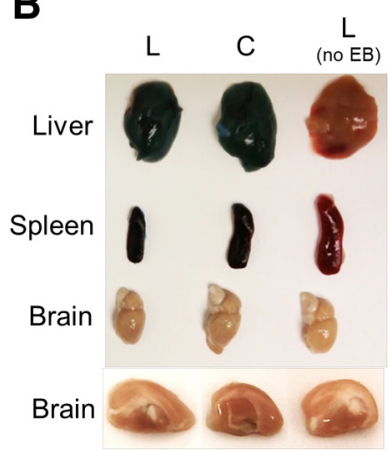

C

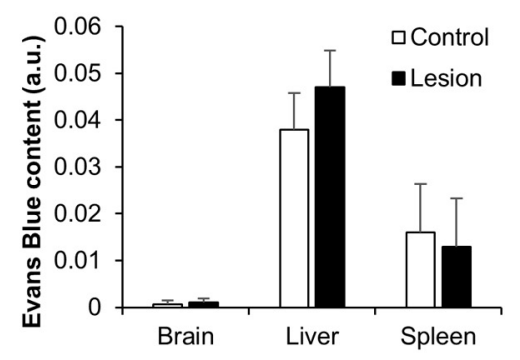

D
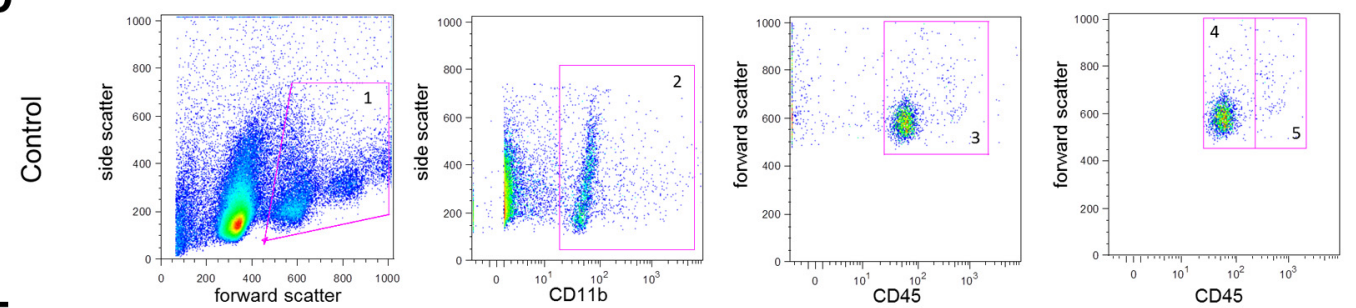

E
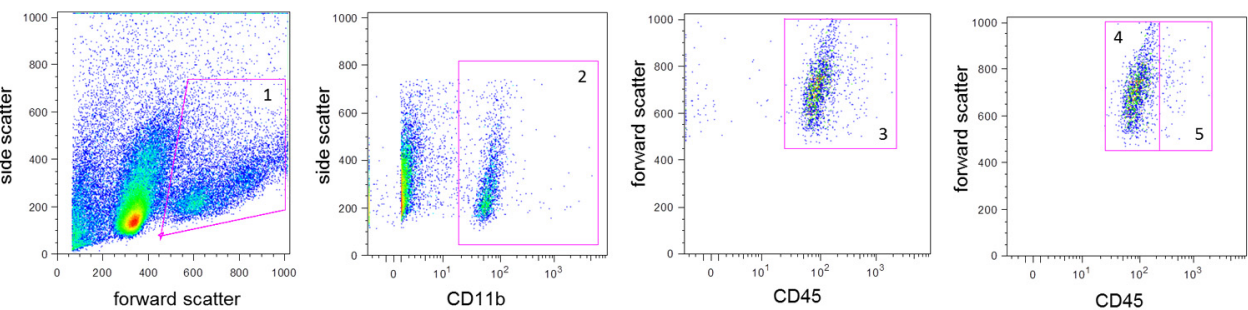

$\mathbf{F}$

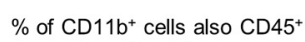
(Box 3)

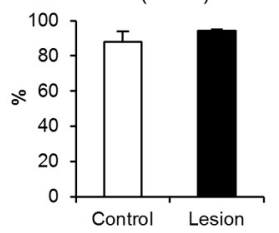

$\%$ CD45 hi of total CD45+ population (Box 5)

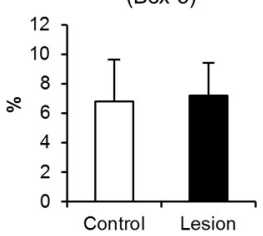

Mean CD45 fluorescence intensity

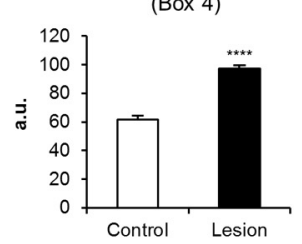

G

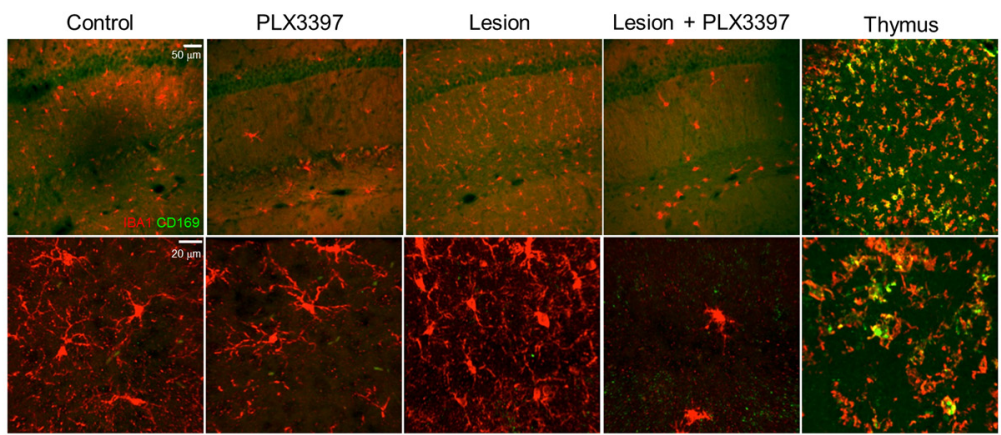

Figure 2. Neuronal lesioning does not induce peripheral cell migration into the brain: $A$, IL-1 $\beta$ levels significantly decrease with $70 \%$ microglial elimination in 2-month-old wild-type mice ( $n=4 /$ group). $\boldsymbol{B}-\boldsymbol{F}$, An additional cohort of 11 month-old CaM/Tet mice (B57BL/6) had doxycycline withdrawn from the diet for $25 \mathrm{~d}$ to induce a neuronal lesion in mice with both transgenes (lesion), and EB was injected on the $25^{\text {th }}$ day of lesion, $6 \mathrm{~h}$ before kill. Single-transgenic mice served as nonlesioning controls (control). $\boldsymbol{B}, E B$ staining was present in the peripheral tissue of all injected mice, but not in the brains of control or lesion mice. C, Quantification of EB absorbance at $595 \mathrm{~nm}$. D, E, Representative flow cytometry analyses for PE-Cy7-CD11b and PE-CD45 in control and lesion mice. Box 1: live cells; Box 2: CD11b ${ }^{+}$cells; Box 3: CD11b ${ }^{+}, C^{2} 45^{+}$cells; Box 4: CD45 $5^{\text {lo/mod }}$ cells; Box 5: CD45 hi cells. F, Quantification revealed no differences between groups in the percentage of $C D 11 b^{+}$cells that were also $C D 45^{+}$(Box 3), nor in the percentage of CD45 ${ }^{\text {hi }}$ cells (Box 5). Mean PE intensity of $C D 45^{\text {lo/mod }}$ cells was significantly higher in lesion compared with control (two-tailed unpaired $t$ test, $p<0.001$; Box 4). G, Twenty times (top row) and $63 \times$ (bottom row) representative images show that regardless of experimental group, IBA1 ${ }^{+}$cells (red channel) in the brain did not stain positively for CD169 (green channel). CD169 positively labeled cells in thymus tissue. ${ }^{*} p<0.05,{ }^{* * * *} p<0.001$. Error bars indicate SEM; $n=3$ /group. 
and Socs1, proinflammatory molecules $B 2 m$ and Bax, the chemokine Ccl19, as well as myeloid-related genes $C c r 2, C d 80, C d 86, H 2 e b 1$, and Ptprc. Critically, microglial elimination after lesioning (lesion + PLX3397) significantly reduced levels of each of these transcripts to that of control (as indicated by the dashed line at $100 \%$ ), or lower. Levels for Tnf- $\alpha$ were below threshold detection levels for all groups.

\section{Microglial elimination normalizes effects of lesion on synaptic markers}

Activated microglia are implicated in synaptic surveillance and stripping following ischemia (Wake et al., 2009). Given the robust and chronic neuroinflammatory response to neuronal lesioning in our model, we wished to determine the effects of both neuronal lesioning and microglial elimination on synaptic surrogates. As microdissected hippocampi were allocated for mRNA analyses, we analyzed immunoreactivity of the presynaptic marker synaptophysin and the postsynaptic marker PSD95 in PFA-fixed tissue. Analyses were performed in the CA1 and stratum radiatum of the hippocampus, as these two regions demonstrated significantly thinner cell layers as a result of $\mathrm{DT}_{\mathrm{A}}$ expression ( $n=7-10$ /group). We found that PSD95 puncta number was largely decreased in the CA1 in both groups of mice that underwent neuronal lesioning (Fig. 4B). Additionally, in both the CA1 and stratum radiatum, PSD95 puncta size was increased in lesion mice. However, treatment with PLX3397 normalized puncta size in lesion mice in both of these hippocampal regions (Fig. 4C,J). Lesioning also greatly increased synaptophysin puncta size and intensity in the CA1 and stratum radiatum. But again, microglial elimination in combination with lesioning normalized this effect, with size and intensity levels of synaptophysin puncta in lesion + PLX3397 mice matching that of controls (Fig. $4 F, G, M, N$ ). On the whole, lesion-induced changes in both PSD95 and synaptophysin puncta were ameliorated with microglial elimination.

\section{Microglial elimination following neuronal lesion improves functional recovery}

Our data show that treatment of lesioned mice with PLX3397 led to the elimination of most microglia, and was coupled with improvements in both inflammatory signaling and synaptic surrogates. To evaluate the functional consequences of microglial elimination after neuronal injury/lesion we performed behavioral testing in these groups of mice during the last week of the study. Performance on elevated plus maze revealed that compared with control mice, mice in the lesion group spent significantly more time in the open arms and significantly less time in the closed arms. However, mice that were treated with PLX3397 for $30 \mathrm{~d}$ following the lesion (lesion + PLX3397) performed similarly to the control and PLX3397 groups (Fig. 5A). Importantly, PLX3397 treatment alone did not affect performance on this task, while the total number of arm entries was similar for all groups (Fig. 5B), indicating a reversal of lesion-induced deficits with elimination of microglia. Mice were next tested in open field, but no differences in behavior were observed among any of the groups (Fig. 5C; time in middle of open field shown). Finally, we tested mice on the Morris water maze to assess both learning and memory abilities, as well as to probe for possible motor deficits. Over the 5 training days of Morris water maze, all four groups learned at a similar rate, though the lesion group (microgliaintact) trended to an increased latency to find the platform on Day 5, whereas the lesion + PLX3397 did not and performed similarly to control and PLX3397 groups (Fig. 5D). Surprisingly, lesioning had no effect on latency to find the platform location during the probe trial, although both groups of mice treated with PLX3397 demonstrated significantly shorter latencies compared with microglia-intact groups (Fig. 5E). No significant differences were found among any of the groups in swim speed or total distance traveled during the probe trial (Fig. $5 F, G$ ). Collectively, these results show that microglia impede recovery following neuronal injury and that this may be mediated through production of inflammatory signals, as well as remodeling of synapses.

\section{Microglia play a protective role during a lesion}

Having determined that microglia play a deleterious role in the brain following neuronal injury/lesioning, we also wished to explore the roles that microglia play during an insult. Additionally, given the effects of microglial elimination on synaptic puncta, we designed an experiment that would also allow us to explore the effects of microglia on dendritic spines, the sites of synaptic connections, in detail. To that end we crossed bitransgenic CaM/Tet$\mathrm{DT}_{\mathrm{A}}$ mice with another transgenic mouse that expresses GFP under elements of the Thy1.1 promoter in forebrain neurons, allowing for sparse expression of GFP (thy1-GFP-M; akin to a Golgi stain) and visualization of dendritic spines in excitatory neurons (Feng et al., 2000). We treated these mice with PLX3397 from the start of the lesioning period $(25 \mathrm{~d})$, and then for an additional $30 \mathrm{~d}$ afterward, consistent with our initial experiment, as shown in Figure $5 A, B$.

As in the non-GFP cohort, microglia are dependent upon signaling through the CSF1R following lesion. Indeed, both direct measures of cell counts and stereology-based estimations found that 85-95\% of all microglia are eliminated with PLX3397 treatment (Fig. 6E,F). Of note, we found far less cell loss within the hippocampus (Fig. $6 G$ ) than in the non-GFP cohort, despite identical lesioning paradigms. It is plausible that the ThylGFP-M transgene interfered with expression of the CaMKII $\alpha$ $\mathrm{tTa}$ or TRE-DT $\mathrm{A}_{\mathrm{A}}$ transgenes, though this needs to be determined empirically, and extends beyond the scope of this report. Notably, lesion alone caused significant layer thinning only in the stratum radiatum. However, both the CA1 and stratum radiatum cell layers were further thinned in mice that lacked microglia during lesioning, suggesting that these cells play a protective role during an insult (Fig. 6G). For further confirmation, we performed stereological counts of neurons using a Cresyl violet stain of the CA1 region, and found that the absence of microglia exacerbated neuronal loss (Fig. $6 H, I$ ), thus confirming that elimination of microglia during an insult results in greater neuronal loss. Despite a lack of overt neuronal loss we did find that lesioning induces microglia to adopt a rod-like morphology and assemble end-to-end in chains, often alongside or even wrapping around neurons in the CA1 (Fig. 6D). Of importance, we found no lesion-induced functional deficits in these mice (Fig. $6 \mathrm{~J}$ ), likely as a result of only a mild lesion being achieved.

Microglia regulate dendritic spine densities in the intact brain Due to the presence of the GFP within excitatory neurons we were able to examine dendritic spine densities and morphologies in the four groups. It has been previously reported that these $\mathrm{CaM} /$ Tet-DT $/ \mathrm{AFP}$ mice show reactive synaptogenesis following lesioning (Castello et al., 2014), resulting in overall increases in spine densities, and therefore we were most interested in the effects of microglial elimination in the nonle- 
A

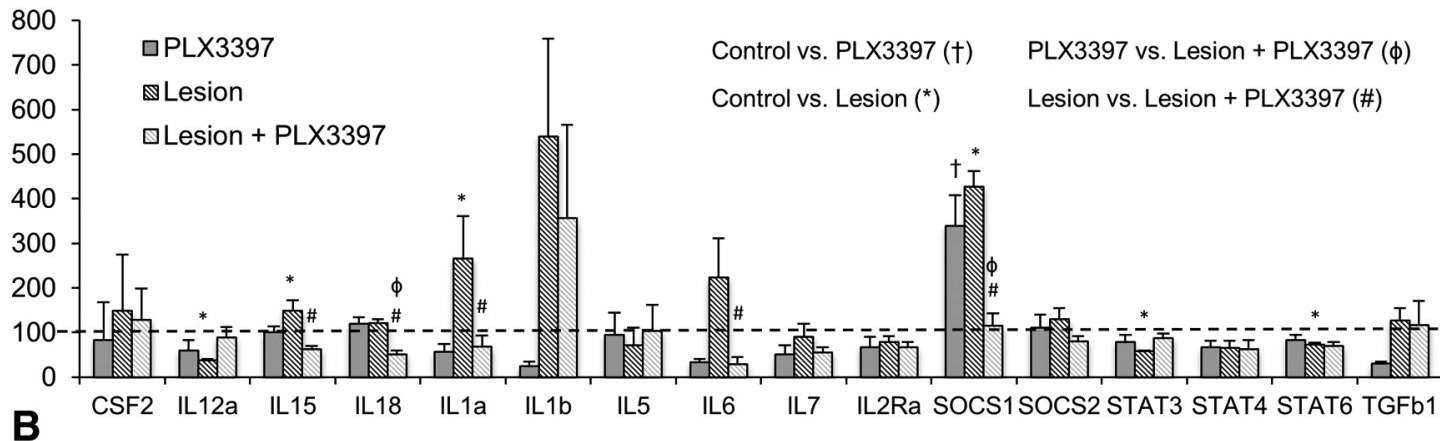

Pro-Inflammatory

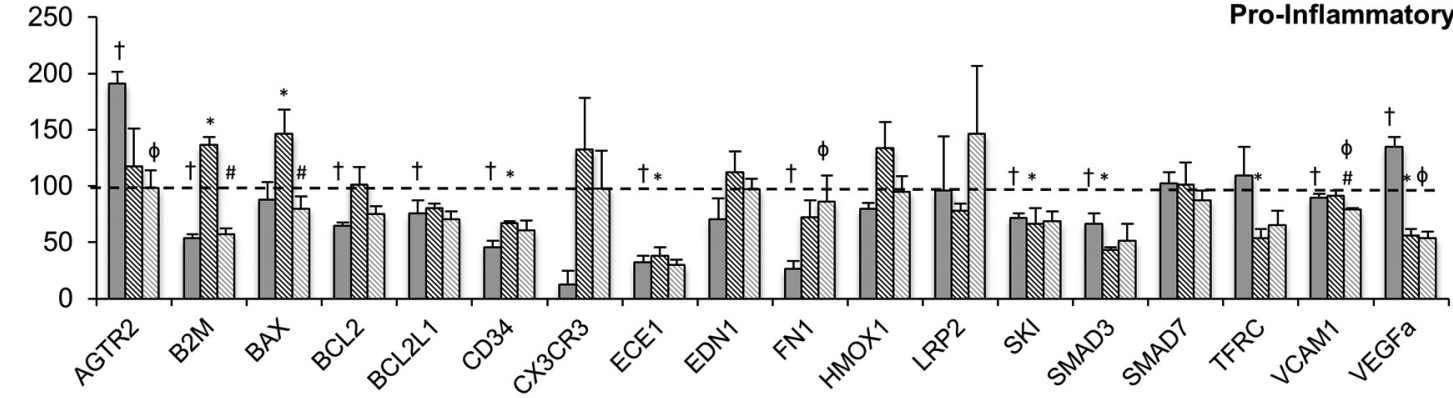

C

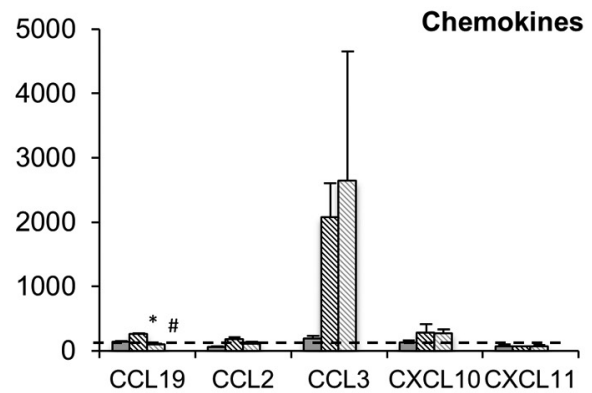

D

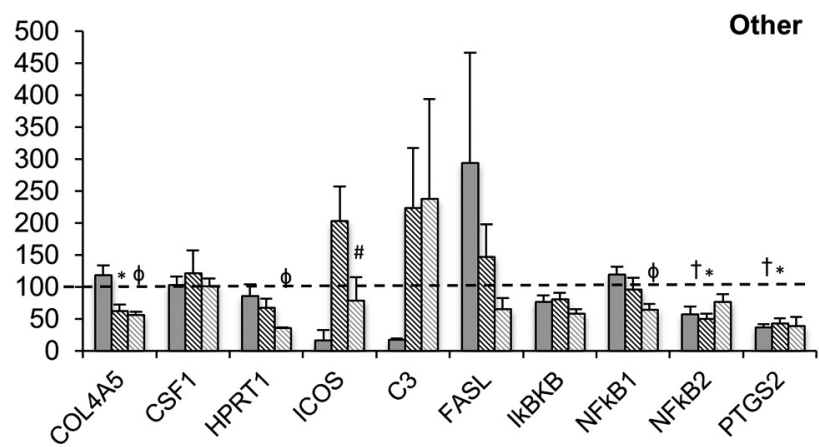

$\mathbf{F}$

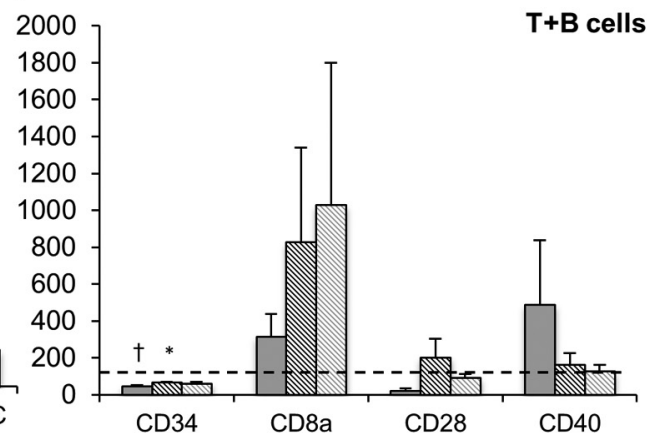

Figure 3. Treatment with PLX3397 reverses lesion-induced increases in inflammatory signaling: Hippocampal mRNA levels for inflammatory transcripts were assessed by real-time PCR; dotted line indicates control, set to 100\%. A, mRNA transcript levels of II-15, II-1 $\alpha$, and Socs 1 were significantly increased with lesion compared with control animals. II-15, II-18, II- $1 \alpha, \| I-6$, and Socs 1 were reduced in animals that were lesioned and treated with PLX3397, compared with animals that were just lesioned. II-12 $\alpha$, Stat3, and Stat6 are significantly decreased with lesion compared with control animals. B, B2m, BCl2, Bcl2l1, Ece1, Fn1, Ski, Smad3, and Vcam mRNA transcript levels were all significantly decreased with PLX3397 treatment, compared with untreated mice. B2m and Bax levels were increased with lesion and restored with PLX3397 treatment, whereas transcript levels of Cd34, Ece 1, Ski, Smad3, Ifrc, and Vegf- $\alpha$ were all decreased with lesion alone compared with control animals. C, C(119 was increased with lesion, compared with control mice, and this effect was inhibited with PLX3397 treatment in lesioned mice. D, Col4a5, Nfkb2, and Ptgs2 levels were decreased with lesion, whereas Nfkb2 and Ptgs 2 levels were also decreased with microglial elimination. E, Levels of $C(\mathrm{Cr} 2$, Cd80, Cd86, H2eb1, and Ptprc were all increased with lesion, compared with control mice, whereas PLX3397 treatment restored these effects in lesioned mice. $C d 4$, $C d 86$, and H2eb1 were all significantly decreased with PLX3397 treatment alone. $F$, Cd34 was significantly reduced with both PLX3397 treatment and lesion compared with control mice. Symbols denote significant differences between groups $(p<0.05)$ : $t$ control versus PLX3397; *control versus lesion; $\phi P L X 3397$ versus lesion + PLX3397; \#lesion versus lesion + PLX3397. Error bars indicate SEM; $n=4 /$ group. 

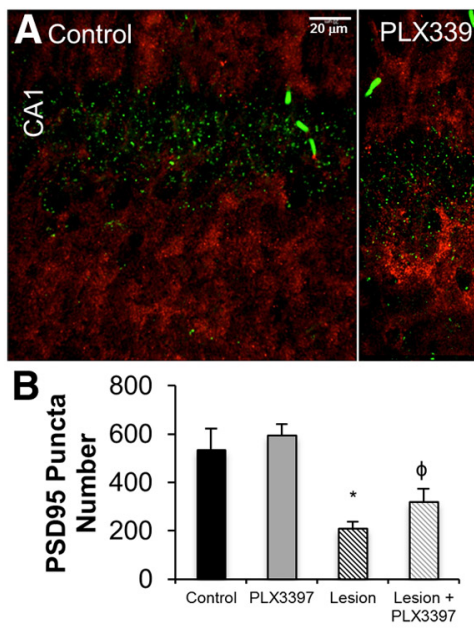

E

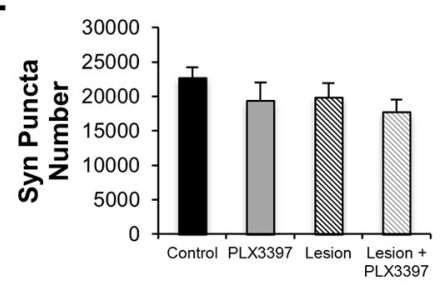

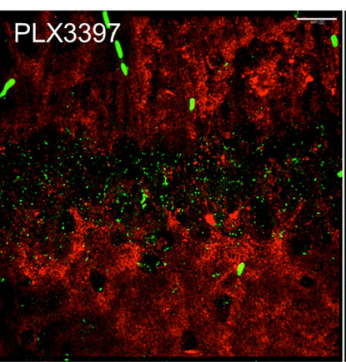

C 20

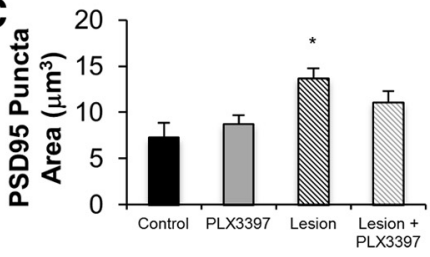

$\mathbf{F}$

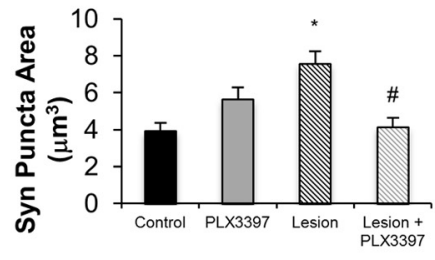

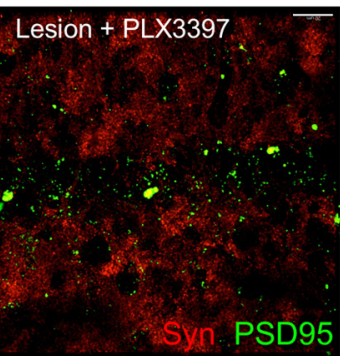

D

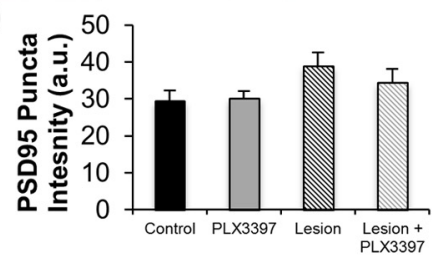

G

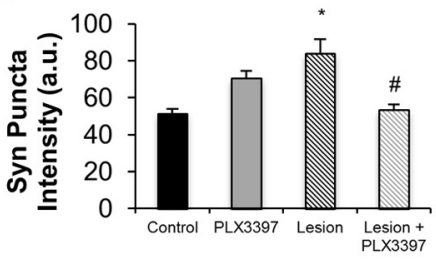

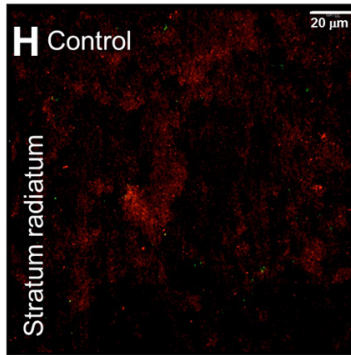
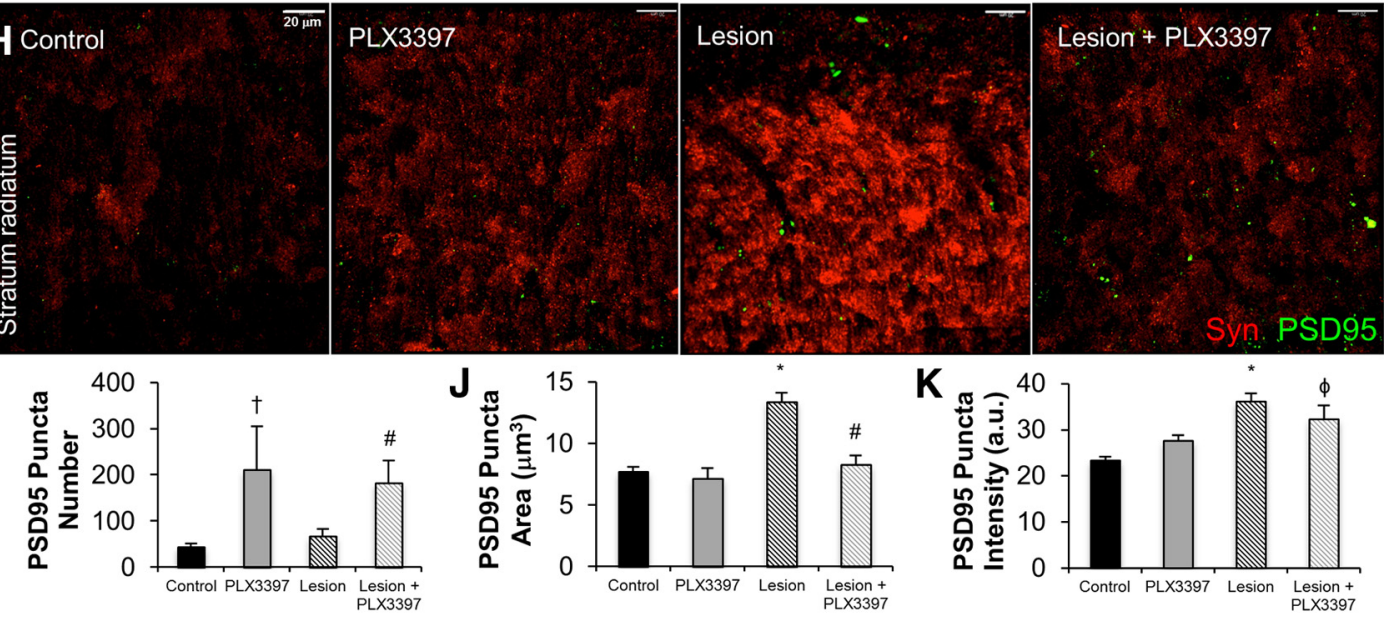

M

N
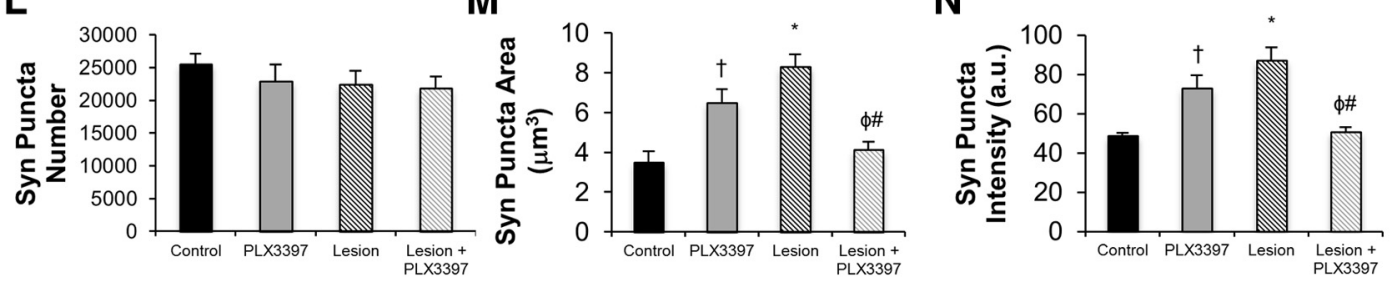

Figure 4. Neuronal lesioning induces synaptic alterations that are restored with subsequent microglial elimination: $\boldsymbol{A}$, Representative $63 \times$ images of PSD95 and synaptophysin immunoreactivity in the CA1 region display alterations in puncta area and size. $\boldsymbol{B}-\boldsymbol{D}$, Quantification of PSD95 puncta number, area, and intensity in the CA1 shows that microglial elimination restores most lesion-induced alterations. $\boldsymbol{E}-\mathbf{G}$, Quantification of synaptophysin puncta number, area, and intensity in the CA1 shows lesion-induced alterations are reversed with PLX3397 treatment. $\boldsymbol{H}$, Representative $63 \times$ images of PSD95 and synaptophysin immunoreactivity in the stratum radiatum. $\mathbf{I} \boldsymbol{K}$, Quantification of PSD95 puncta number, area, and intensity in the stratum radiatum reveals increases in puncta number with microglial elimination. $\boldsymbol{L}-\mathbf{N}$, Quantification of synaptophysin puncta number, area, and intensity in stratum radiatum reveals changes in puncta area and intensity with PLX3397 and/or lesion. Symbols denote significant differences between groups $(p<0.05)$ : †control versus PLX3397; ${ }^{*}$ control versus lesion; $\phi P L X 3397$ versus lesion + PLX3397; \#lesion versus lesion + PLX3397. Error bars indicate SEM; $n=7-10$ /group.

sioned mice, and the combination of lesion and microglialelimination. We confirmed increases in spine densities in CA1 apical nonprimary dendrites following lesioning, and found that elimination of microglia alone led to a robust $35 \%$ increase in spine density (Fig. 7B). Increases in dendritic spines due to microglial elimination were not indiscriminate: 8 week elimination of microglia increased mushroom spines by $44 \%$ and thin spines by $71 \%$, but decreased stubby spines by $55 \%$. Interestingly, the combination of lesion and microglial elimination did not further increase overall spine numbers, though 
A

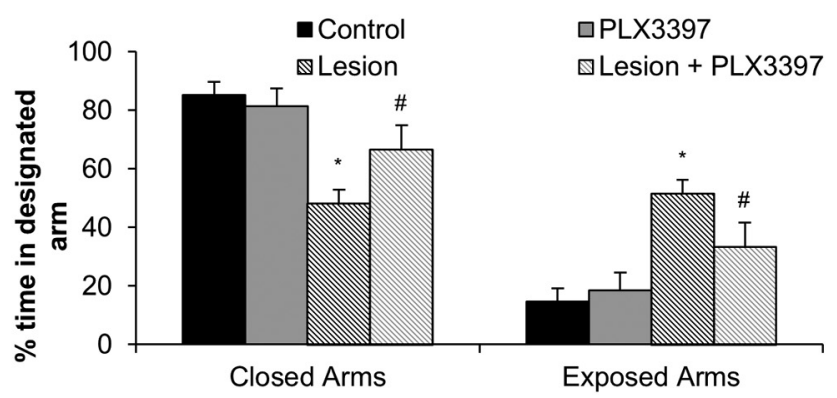

C

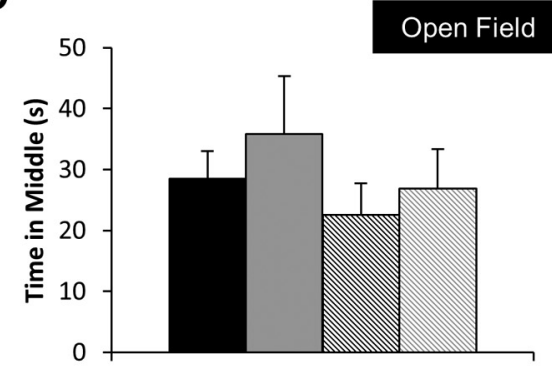

D

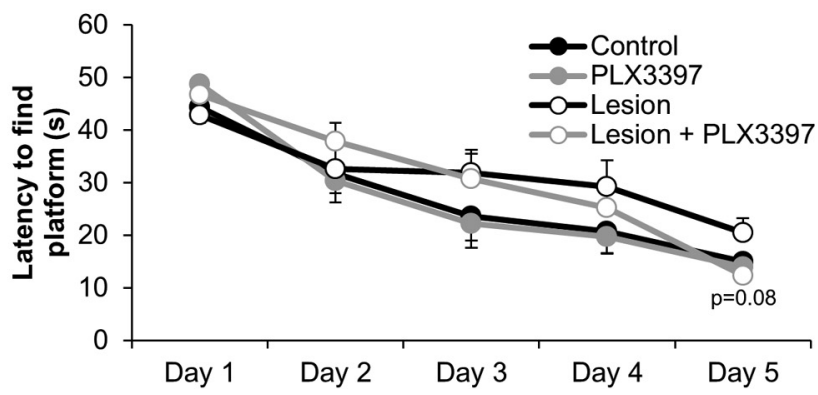

$\mathbf{F}$

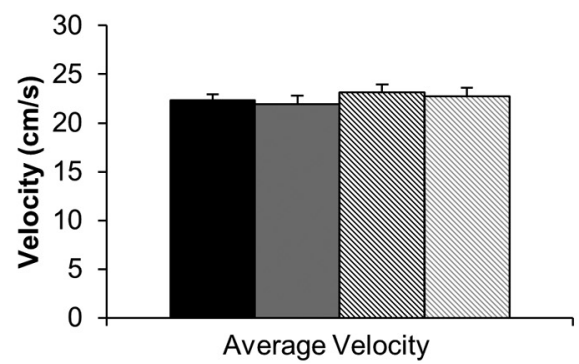

B

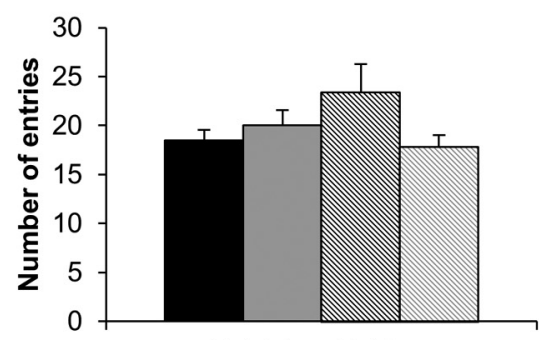

Total Arm Entries
E

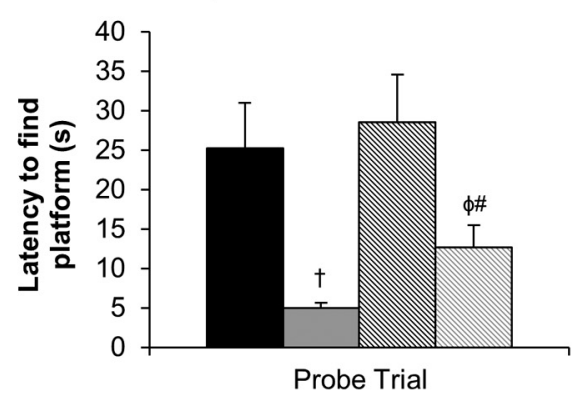

G

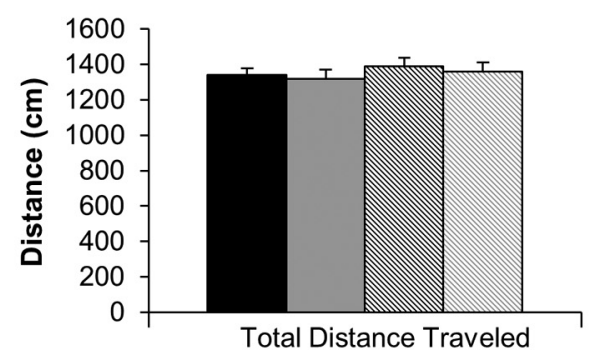

Figure 5. Elimination of microglia following extensive neuronal loss improves functional recovery: $A$, Lesion mice spent less time in closed arms and more time in open arms on the elevated plus maze test, compared with control mice (via two-way ANOVA, main effect of lesion $p=0.0006$ ). Lesion + PLX3397 mice performed similarly to control and PLX3397 groups in both closed and exposed arms. $\boldsymbol{B}$, All four groups of mice had comparable numbers of arm entries. $\boldsymbol{C}$, All four groups of mice spent similar amounts of time in the middle arena of open field testing apparatus. $\boldsymbol{D}$, All mice learned over the $5 \mathrm{~d}$ training period, though the lesion group trended to a longer latency to find platform on Day 5 , compared with lesion $+\mathrm{PLX} 3397 \mathrm{group}(p=0.0882) . \boldsymbol{E}$, Treatment with PLX3397 increased performance on the probe trial (via two-way ANOVA, main effect of treatment $p=0.0007$ ). $\boldsymbol{F}, \mathbf{G}$, All four groups of mice demonstrated comparable swim speeds and distance traveled during the probe trial. Symbols denote significant differences between groups $(p<0.05)$ : †control versus PLX3397; ${ }^{*}$ control versus lesion; $\phi P L X 3397$ versus lesion $+\mathrm{PLX3397;} \mathrm{\# lesion}$ versus lesion + PLX3397. Error bars indicate SEM; $n=7-10 /$ group.

it is possible that a physiological upper threshold of this effect was reached.

To determine whether the effects of microglial elimination are global, we also analyzed spine type and number in pyramidal cells in layer 5 of the primary visual cortex (V1), a site away from the focal point of the neuronal insult. Similar increases in dendritic spine numbers were seen with microglial elimination, though importantly, not with lesion alone (Fig. 7D). Again, mushroom and thin spines were increased and stubby spines decreased in PLX3397 mice compared with controls. Representative images of dendrites in the CA1 and layer 5 of V1 are shown in Figure $7 A$ and $C$, respectively. These data suggest that it is the local environmen- 

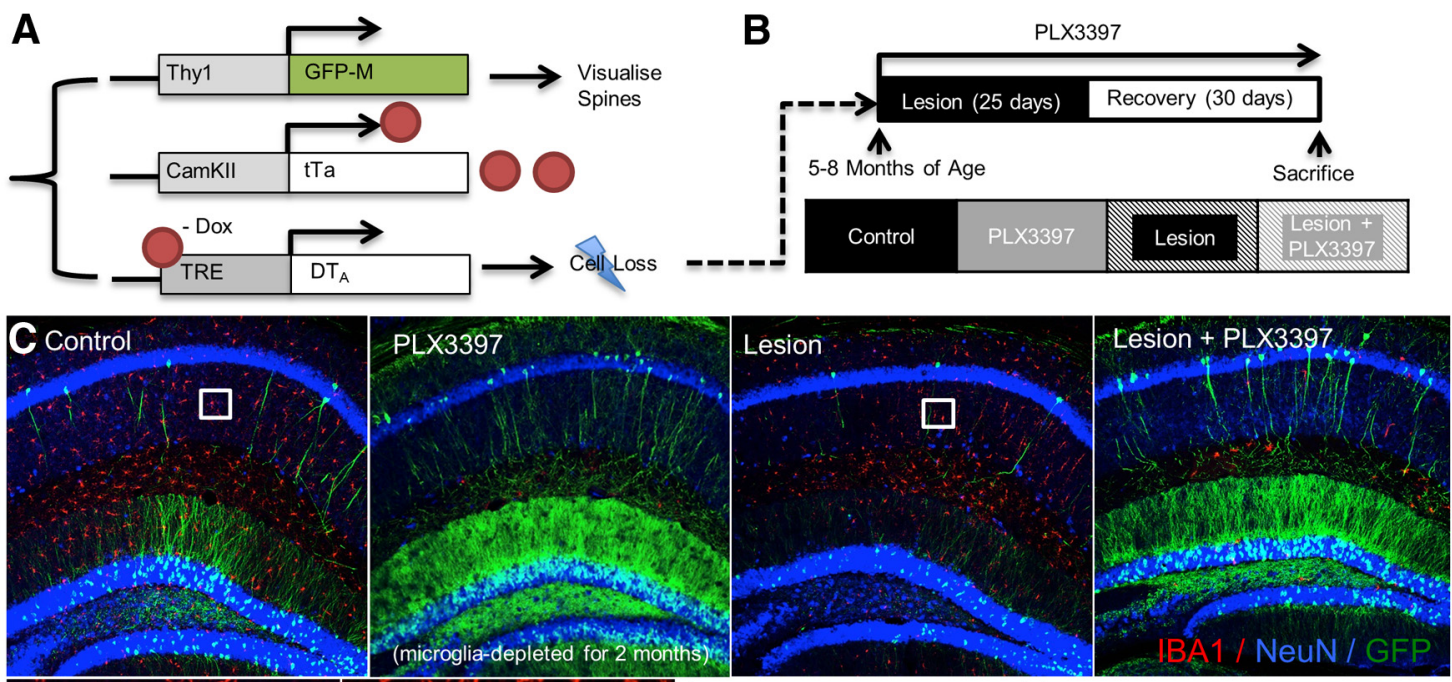

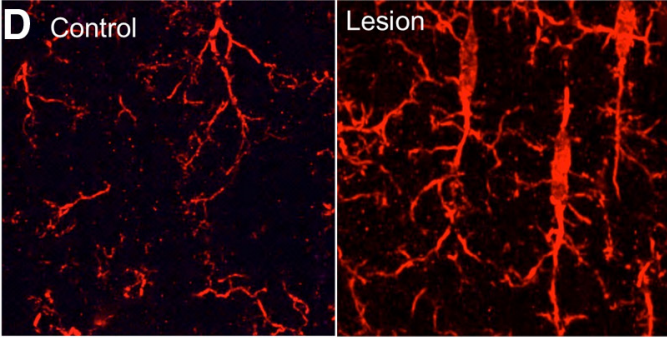

G

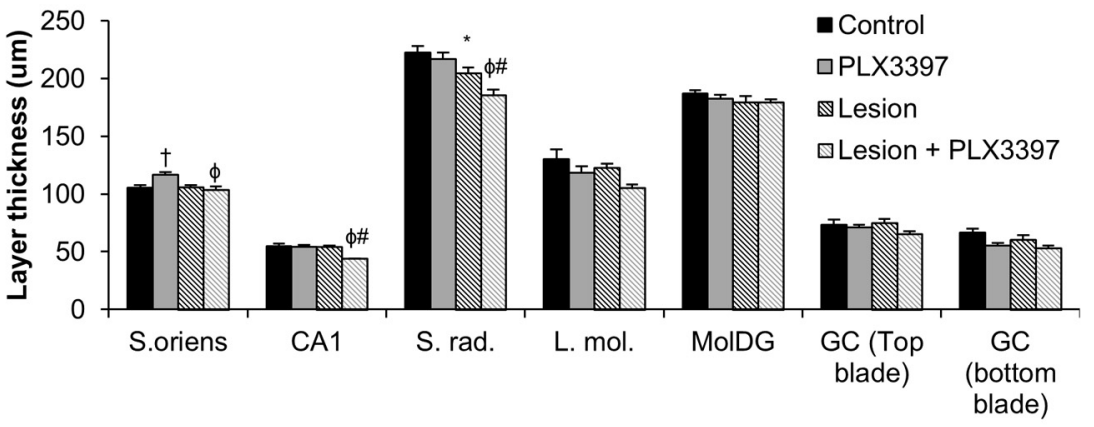

H
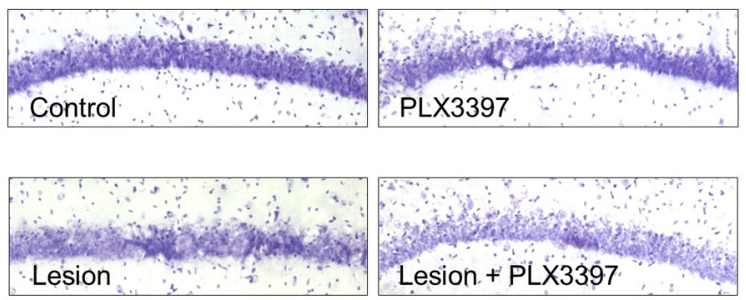

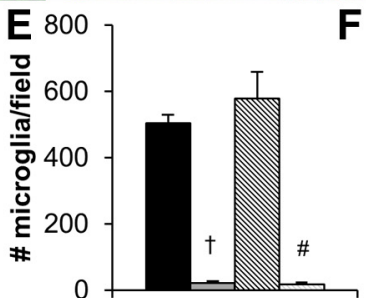

1
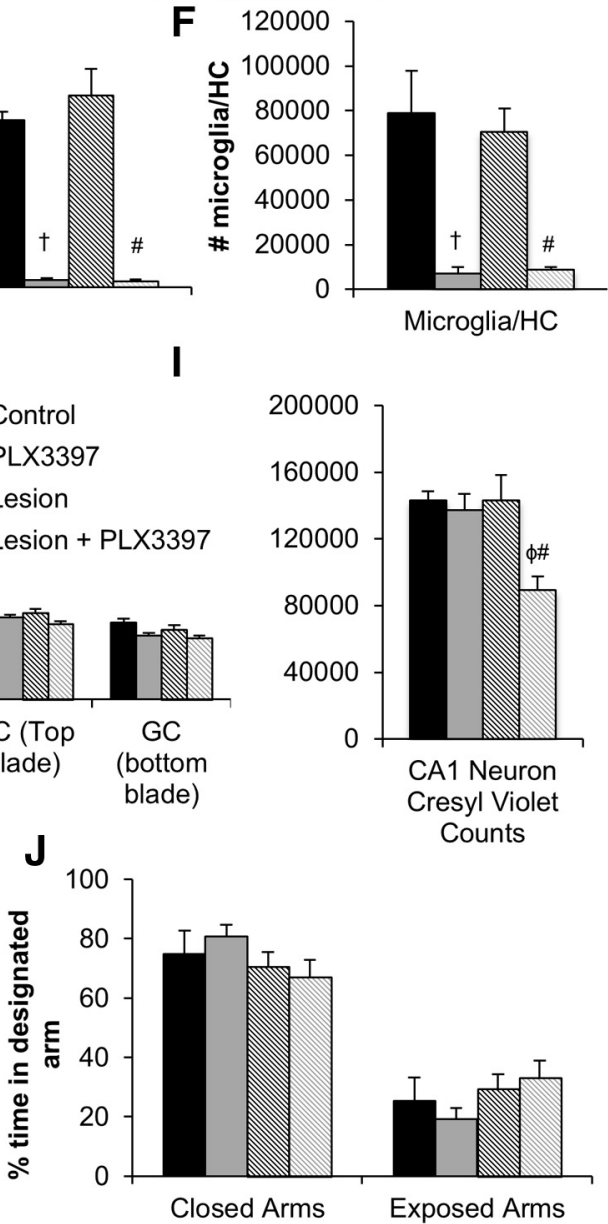

Figure 6. Microglial elimination in thy1-GFP-M expressing CaM/Tet mice: 5 - to 8-month-old GFP-CaM/Tet mice (C57BL/6-CBA mix) were treated with $290 \mathrm{mg} / \mathrm{kg}$ PLX3397 for $2 \mathrm{months}$ to deplete microglia. A 25 d neuronal lesion was induced in one-half of the animals at the same time treatment with PLX3397 began. $A, B$, Schematics of GFP-CaM/Tet mouse model of inducible neuronal loss and experimental design. C, Representative 10X confocal images of the hippocampal region from each group for neuronal nuclei (NEUN in blue channel), microglia (IBA1 in red channel), and GFP in the green channel. $\boldsymbol{D}$, Representative $63 \times$ IBA1 immunofluorescent staining from the hippocampal region showing rod like morphologies with lesion. $\boldsymbol{E}$, Quantification of microglia in the field-of-view by automated, direct cell counting reveals a significant decrease in both PLX3397-treated groups. $F$, Estimation of microglia per hippocampus by stereological methods also reveals a significant decrease in both PLX3397-teated groups. $\boldsymbol{G}$, Quantification of the thickness of the hippocampal layers reveals a significant lesion-induced decrease only in the stratum radiatum. $\boldsymbol{H}$, Representative $20 \times$ pictures of Cresyl Violet staining in the CA1 cell layer from each group. I, Stereological estimation of neurons in the CA1 region from each group reveals a significant decrease only in the lesion + PLX3397 group. J, Lesion mice did not display a deficit in performance on elevated plus maze. Symbols denote significant differences between groups ( $p<0.05): t c o n t r o l$ versus PLX3397; * control versus lesion; $\phi$ PLX3397 versus lesion + PLX3397; \#lesion versus lesion + PLX3397. Error bars indicate SEM; $n=5-6 /$ group. 
A CA1

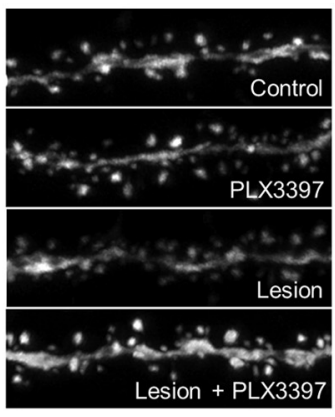

\section{V1 Layer 5}

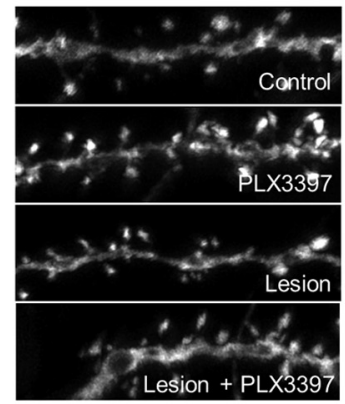

B
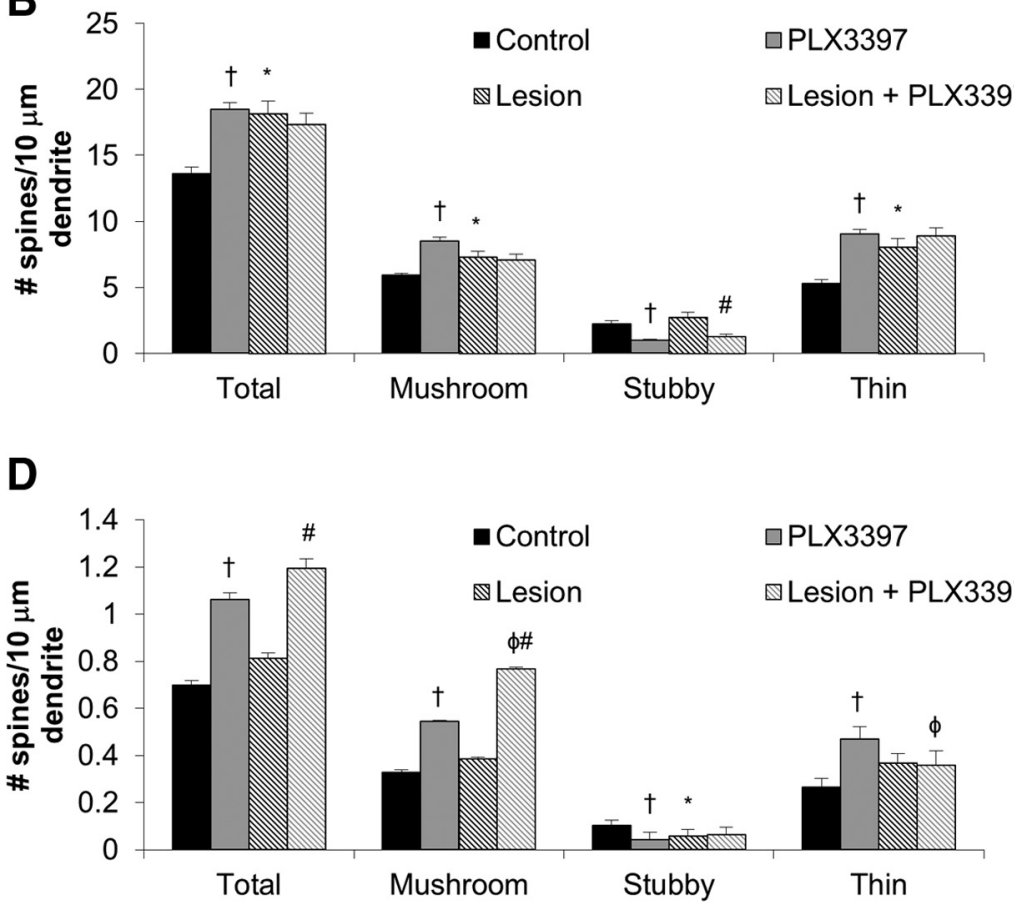

Figure 7. Microglial elimination increases dendritic spine densities throughout the brain. $A$, Representative images of dendrites from the CA1 region. $\boldsymbol{B}$, Quantification of dendritic spines, overall and by type, in the CA1 region reveals lesion- and PLX3397-associated increases. C, Representative images of dendrites from layer 5 in V1. D, Quantification of dendritic spines, overall and by type, in layer 5 of $\mathrm{V} 1$ reveals only PLX3397-associated increases. Symbols denote significant differences between groups $(p<0.05)$ : $t$ control versus PLX3397; * control versus lesion; $\phi$ PLX3397 versus lesion + PLX3397; \#lesion versus lesion + PLX3397. Error bars indicate SEM; $n=5 /$ group.

tal response to the lesion that produces a change in spine number, whereas microglial elimination globally increases spine numbers.

\section{Discussion}

Upon neural insult or invasion by a pathogenic species, microglia become activated and secrete proinflammatory cytokines such as TNF- $\alpha$, IL- $1 \beta$, and IL-6, and subsequently assume an antiinflammatory role, secreting molecules such as IL-4 and IL-10 as part of the resolution and tissue repair process (Colton and Wilcock, 2010). However, with severe insults like traumatic brain injury (TBI) or chronic neurodegenerative conditions, microglia remain activated, and in this way, are believed to contribute to cognitive decline. We hypothesized that eliminating microglia after a severe neuronal lesion would partially attenuate functional deficits caused by the insult, by way of reducing proinflammatory signaling, as well as any harmful interactions microglia may have with the local brain environment. We previously discovered that microglia are critically dependent on signaling through the CSF1R for their survival in the adult mouse brain (Elmore et al., 2014), but had not extended these studies to look at microglia in disease/activation states. To that end, we used a genetic hippocampal lesion model that results in extensive neuronal loss and chronic microglia-evoked neuroinflammation, as this model has relevance to TBI, stroke, hippocampal sclerosis, and Alzheimer's disease. Crucially, we find that these chronically activated microglia are indeed dependent on CSF1R signaling, as we are still able to successfully eliminate the vast majority of microglia from the CNS following lesioning, through administration of the smallmolecule CSF1R inhibitor PLX3397. This finding allows researchers to eliminate microglia from any disease or injury state and directly determine the roles that these cells play.

By eliminating microglia either during or after lesioning, we were able to parse protective versus harmful effects that these cells exert in the brain. For example, we found that the elimination of microglia for $30 \mathrm{~d}$ following neuronal lesioning results in partial restoration of deficits on the elevated plus maze, revealing that these cells impair recovery after injury. Curiously, we did not find lesion-induced deficits during the probe trial of Morris water maze testing. However, we suspect that the interim period of time between the end of lesioning and the beginning of behavioral testing could allow for the recovery of some lesion-induced deficits. Indeed, a study recently showed that lesioned CaM/Tet$\mathrm{DT}_{\mathrm{A}}$ mice exhibit deficits 1 month postlesion, but not 3 months postlesion, on the $24 \mathrm{~h}$ probe trial of the Barnes maze, a hippocampal-dependent measure of memory (Myczek et al., 2014).

To explore possible mechanisms by which elimination of microglia following injury might promote recovery we performed inflammatory profiling. Microglia are immune competent cells and produce and secrete a plethora of signaling molecules, as well as cellular toxins such as reactive oxygen species, depending on their activation state (Colton and Wilcock, 2010). Of the inflammation-related genes that we measured, lesioning induced an upregulation in expression of 11 genes, but subsequent microglial elimination was able to reduce expression of all these transcripts to that of control levels, or lower. Thus, elimination of microglia also eliminates the substances that they produce, which may negatively affect the local parenchyma. Of note, injury is known to promote the infiltration of peripheral myeloid cells into the brain, such as monocytes and macrophages (Beschorner et al., 2002; Fiala et al., 2002; Schilling et al., 2009). However, we did not find the blood-brain barrier to be compromised in this lesion model, nor did we find an increase in the number of CD $45^{\text {hi }}$ cells in the lesioned brain. Moreover, IBA1 ${ }^{+}$cells in the brain did not appear to be derived from peripheral myeloid cells, 
as assessed by immunolabeling for CD169. Thus, our lesioning paradigm does not induce the infiltration of peripheral myeloid cells to the brain, and $\mathrm{IBA}^{+}$cells that remain after PLX3397 treatment appear to be microglia that escape elimination.

It is also important to consider the physical interactions that microglia have with their local environment. It is known that microglia also have roles as synaptic architects, at least in the developing brain (Paolicelli et al., 2011; Schafer et al., 2012). Microglia are highly branched and motile, forming frequent physical interactions with synapses (Perry and O'Connor, 2010; Yirmiya and Goshen, 2011). In addition, they possess phagocytic activity, and are therefore ideally suited to regulate the synaptic landscape. In this study we explored the effects of both lesioning and microglial elimination on the presynaptic protein synaptophysin, as well as the postsynaptic protein PSD95. We focused on the CA1 and stratum radiatum of the hippocampus, where significant neuronal loss occurred. With microglial elimination, we observed reversals of lesion-induced alterations in the size and intensity of synaptic puncta. The lesion-associated loss of puncta number is not surprising given the overt cell loss, and it is plausible that remaining puncta increase in size to compensate for the loss in overall number. In parallel with these data, another group found that systemic administration of lipopolysaccharide decreased the number, but increased the volume, of PSD95 puncta in wild-type mice (Valero et al., 2014).

In contrast to the harmful effects that microglia exert following lesion, microglial elimination during the lesion period promoted hippocampal neuronal loss of $>35 \%$, as measured by stereology. Thus, the presence of microglia during an insult appears to support neuronal survival, revealing divergent roles for these cells depending upon the insult phase.

\section{Microglia regulate dendritic spine densities in the adult brain} Using $\mathrm{CaM} / \mathrm{Tet}-\mathrm{DT}_{\mathrm{A}} / \mathrm{GFP}$ mice we were able to explore the effects of long-term microglial elimination on dendritic spine densities and morphologies. In the developing brain, microglia are involved in activity- and complement-dependent pruning by phagocytosing presynaptic inputs (Schafer et al., 2012), as well as in a CX3CL1-CX3CR1-dependent fashion (Paolicelli et al., 2011; Zhan et al., 2014). Ex vivo evidence suggests that microglia can shape glutamatergic signaling at both presynaptic and postsynaptic sites, resulting in changes in the electrophysiological properties of primary P3-P7 neurons (Schafer et al., 2012; Ji et al., 2013). Additionally, short-term elimination of microglia from P30 mice demonstrated marked changes in dendritic spine dynamics, due to a lack of microglia-derived BDNF signaling (Parkhurst et al., 2013). Crucially, we find that microglial elimination leads to large increases in spine number in all brain regions surveyed, indicating that microglia play substantial roles in the maintenance of dendritic spine densities in the adult brain, in addition to the roles described in the developing brain. Such an opportunity to manipulate dendritic spine number and type in the adult brain merits further research by the field, and could have far-ranging implications for conditions in which aberrant spine regulation is present, including neurodegenerative diseases, autism, and multiple forms of mental retardation.

Overall, our data reveal that the elimination of microglia facilitates functional recovery following neuronal lesioning. Thus, microglia are harmful to the CNS following injury, and we can negate these effects through their elimination with CSF1R inhibitors. Although the elimination of an entire cell type has broad effects, it is likely a combination of a reduction in the inflammotoxic substances normally produced by microglia, as well as the removal of their physical interactions with other cells types, such as neurons, that underlies these functional benefits.

\section{References}

Baglietto-Vargas D, Medeiros R, Martinez-Coria H, LaFerla FM, Green KN (2013) Mifepristone alters amyloid precursor protein processing to preclude amyloid beta and also reduces tau pathology. Biol Psychiatry 74: 357-366. CrossRef Medline

Beschorner R, Nguyen TD, Gözalan F, Pedal I, Mattern R, Schluesener HJ, Meyermann R, Schwab JM (2002) CD14 expression by activated parenchymal microglia/macrophages and infiltrating monocytes following human traumatic brain injury. Acta Neuropathologica 103:541-549. CrossRef Medline

Butovsky O, Siddiqui S, Gabriely G, Lanser AJ, Dake B, Murugaiyan G, Doykan CE, Wu PM, Gali RR, Iyer LK, Lawson R, Berry J, Krichevsky AM, Cudkowicz ME, Weiner HL (2012) Modulating inflammatory monocytes with a unique microRNA gene signature ameliorates murine ALS. J Clin Invest 122:3063-3087. CrossRef Medline

Castello NA, Nguyen MH, Tran JD, Cheng D, Green KN, LaFerla FM (2014) 7,8-Dihydroxyflavone, a small molecule TrkB agonist, improves spatial memory and increases thin spine density in a mouse model of Alzheimer disease-like neuronal loss. PloS One 9:e91453. CrossRef Medline

Colton C, Wilcock DM (2010) Assessing activation states in microglia. CNS Neurol Disord Drug Targets 9:174-191. CrossRef Medline

D’Mello C, Le T, Swain MG (2009) Cerebral microglia recruit monocytes into the brain in response to tumor necrosis factor $\alpha$ signaling during peripheral organ inflammation. J Neurosci 29:2089-2102. CrossRef Medline

Elmore MR, Najafi AR, Koike MA, Dagher NN, Spangenberg EE, Rice RA, Kitazawa M, Matusow B, Nguyen H, West BL, Green KN (2014) Colony-stimulating factor 1 receptor signaling is necessary for microglia viability, unmasking a microglia progenitor cell in the adult brain. Neuron 82:380-397. CrossRef Medline

Erblich B, Zhu L, Etgen AM, Dobrenis K, Pollard JW (2011) Absence of colony stimulation factor-1 receptor results in loss of microglia, disrupted brain development and olfactory deficits. PLoS One 6:e26317. CrossRef Medline

Feng G, Mellor RH, Bernstein M, Keller-Peck C, Nguyen QT, Wallace M, Nerbonne JM, Lichtman JW, Sanes JR (2000) Imaging neuronal subsets in transgenic mice expressing multiple spectral variants of GFP. Neuron 28:41-51. CrossRef Medline

Fiala M, Liu QN, Sayre J, Pop V, Brahmandam V, Graves MC, Vinters HV (2002) Cyclooxygenase-2-positive macrophages infiltrate the Alzheimer's disease brain and damage the blood-brain barrier. Eur J Clin Invest 32:360-371. CrossRef Medline

Gao L, Brenner D, Llorens-Bobadilla E, Saiz-Castro G, Frank T, Wieghofer P, Hill O, Thiemann M, Karray S, Prinz M, Weishaupt JH, Martin-Villalba A (2015) Infiltration of circulating myeloid cells through CD95L contributes to neurodegeneration in mice. J Exp Med 212:469-480. CrossRef Medline

Greter M, Heppner FL, Lemos MP, Odermatt BM, Goebels N, Laufer T, Noelle RJ, Becher B (2005) Dendritic cells permit immune invasion of the CNS in an animal model of multiple sclerosis. Nat Med 11:328-334. CrossRef Medline

Ji K, Akgul G, Wollmuth LP, Tsirka SE (2013) Microglia actively regulate the number of functional synapses. PloS One 8:e56293. CrossRef Medline

Kitazawa M, Cheng D, Tsukamoto MR, Koike MA, Wes PD, Vasilevko V, Cribbs DH, LaFerla FM (2011) Blocking IL-1 signaling rescues cognition, attenuates tau pathology, and restores neuronal beta-catenin pathway function in an Alzheimer's disease model. J Immunol 187: 6539-6549. CrossRef Medline

Kochi SK, Collier RJ (1993) DNA fragmentation and cytolysis in U937 cells treated with diphtheria toxin or other inhibitors of protein synthesis. Exp Cell Res 208:296-302. CrossRef Medline

Lee P, Morley G, Huang Q, Fischer A, Seiler S, Horner JW, Factor S, Vaidya D, Jalife J, Fishman GI (1998) Conditional lineage ablation to model human diseases. Proc Natl Acad Sci U S A 95:11371-11376. CrossRef Medline

Liu JS, Amaral TD, Brosnan CF, Lee SC (1998) IFNs are critical regulators of IL-1 receptor antagonist and IL-1 expression in human microglia. J Immunol 161:1989-1996. Medline

Mayford M, Bach ME, Huang YY, Wang L, Hawkins RD, Kandel ER (1996) 
Control of memory formation through regulated expression of a CaMKII transgene. Science 274:1678-1683. CrossRef Medline

Myczek K, Yeung ST, Castello N, Baglietto-Vargas D, LaFerla FM (2014) Hippocampal adaptive response following extensive neuronal loss in an inducible transgenic mouse model. PloS One 9:e106009. CrossRef Medline

Neely KM, Green KN, LaFerla FM (2011) Presenilin is necessary for efficient proteolysis through the autophagy-lysosome system in a gammasecretase-independent manner. J Neurosci 31:2781-2791. CrossRef Medline

Nimmerjahn A, Kirchhoff F, Helmchen F (2005) Resting microglial cells are highly dynamic surveillants of brain parenchyma in vivo. Science 308: 1314-1318. CrossRef Medline

Paolicelli RC, Bolasco G, Pagani F, Maggi L, Scianni M, Panzanelli P, Giustetto M, Ferreira TA, Guiducci E, Dumas L, Ragozzino D, Gross CT (2011) Synaptic pruning by microglia is necessary for normal brain development. Science 333:1456-1458. CrossRef Medline

Parkhurst CN, Yang G, Ninan I, Savas JN, Yates JR 3rd, Lafaille JJ, Hempstead BL, Littman DR, Gan WB (2013) Microglia promote learningdependent synapse formation through brain-derived neurotrophic factor. Cell 155:1596-1609. CrossRef Medline

Perry VH, O'Connor V (2010) The role of microglia in synaptic stripping and synaptic degeneration: a revised perspective. ASN Neuro 2:e00047. CrossRef Medline

Pessac B, Godin I, Alliot F (2001) [Microglia: origin and development]. Bulletin de l'Academie nationale de medecine 185:337-346; discussion 346347. Medline

Peters A, Kaiserman-Abramof IR (1970) The small pyramidal neuron of the rat cerebral cortex: the perikaryon, dendrites and spines. Am J Anat 127: 321-355. CrossRef Medline

Ramlackhansingh AF, Brooks DJ, Greenwood RJ, Bose SK, Turkheimer FE, Kinnunen KM, Gentleman S, Heckemann RA, Gunanayagam K, Gelosa G, Sharp DJ (2011) Inflammation after trauma: microglial activation and traumatic brain injury. Ann Neurol 70:374-383. CrossRef Medline

Renno T, Krakowski M, Piccirillo C, Lin JY, Owens T (1995) TNF-alpha expression by resident microglia and infiltrating leukocytes in the central nervous system of mice with experimental allergic encephalomyelitis: regulation by Th1 cytokines. J Immunol 154:944-953. Medline

Schafer DP, Lehrman EK, Kautzman AG, Koyama R, Mardinly AR, Yamasaki
R, Ransohoff RM, Greenberg ME, Barres BA, Stevens B (2012) Microglia sculpt postnatal neural circuits in an activity and complementdependent manner. Neuron 74:691-705. CrossRef Medline

Schilling M, Strecker JK, Schäbitz WR, Ringelstein EB, Kiefer R (2009) Effects of monocyte chemoattractant protein 1 on blood-borne cell recruitment after transient focal cerebral ischemia in mice. Neuroscience 161: 806-812. CrossRef Medline

Sierra A, Gottfried-Blackmore AC, McEwen BS, Bulloch K (2007) Microglia derived from aging mice exhibit an altered inflammatory profile. Glia 55:412-424. CrossRef Medline

Tobinick EL, Gross H (2008) Rapid cognitive improvement in Alzheimer's disease following perispinal etanercept administration. J Neuroinflammation 5:2. CrossRef Medline

Valero J, Mastrella G, Neiva I, Sánchez S, Malva JO (2014) Long-term effects of an acute and systemic administration of LPS on adult neurogenesis and spatial memory. Front Neurosci 8:83. CrossRef Medline

Wake H, Moorhouse AJ, Jinno S, Kohsaka S, Nabekura J (2009) Resting microglia directly monitor the functional state of synapses in vivo and determine the fate of ischemic terminals. J Neurosci 29:3974-3980. CrossRef Medline

Wirenfeldt M, Babcock AA, Ladeby R, Lambertsen KL, Dagnaes-Hansen F, Leslie RG, Owens T, Finsen B (2005) Reactive microgliosis engages distinct responses by microglial subpopulations after minor central nervous system injury. J Neurosci Res 82:507-514. CrossRef Medline

Wohleb ES, Powell ND, Godbout JP, Sheridan JF (2013) Stress-induced recruitment of bone marrow-derived monocytes to the brain promotes anxiety-like behavior. J Neurosci 33:13820-13833. CrossRef Medline

Yamasaki TR, Blurton-Jones M, Morrissette DA, Kitazawa M, Oddo S, LaFerla FM (2007) Neural stem cells improve memory in an inducible mouse model of neuronal loss. J Neurosci 27:11925-11933. CrossRef Medline

Yirmiya R, Goshen I (2011) Immune modulation of learning, memory, neural plasticity and neurogenesis. Brain Behav Immun 25:181-213. CrossRef Medline

Zhan Y, Paolicelli RC, Sforazzini F, Weinhard L, Bolasco G, Pagani F, Vyssotski AL, Bifone A, Gozzi A, Ragozzino D, Gross CT (2014) Deficient neuron-microglia signaling results in impaired functional brain connectivity and social behavior. Nat Neurosci 17:400-406. CrossRef Medline 